\title{
A dynamic opportunistic maintenance model to maximize energy-based availability while reducing the life cycle cost of wind farms
}
A. Erguido ${ }^{\mathrm{a}, \mathrm{b}}$, A. Crespo Márquez ${ }^{\mathrm{b}}$, E. Castellano ${ }^{\mathrm{c}}, \mathrm{J}$. Gómez Fernández ${ }^{\mathrm{b}}$

${ }^{a}$ Departamento de Organización Industrial y Gestión de Empresas I, Escuela Superior de Ingenieros, Universidad de Sevilla.

${ }^{b}$ IK4-Ikerlan Technology Research Centre, Operations and Maintenance Technologies Area, 20500 Gipuzkoa, Spain

${ }^{c}$ MIK Research Centre, Mondragon University, 20560 Gipuzkoa, Spain

*Asier Erguido (corresponding author)

aerguido@ikerlan.es

+34943712400

Adolfo Crespo

adolfo@etsi.us.es

+34954487215

Eduardo Castellano

ecastellano@mondragon.edu

+34943718009

Juan Fco. Gómez

juan.gomez@iies.es

+34954487215

\section{Funding}

This research work was performed within both the context of the EmaitekPlus 2015-2016 Program of the Basque Government and the SustainOwner ('Sustainable Design and Management of Industrial Assets through Total Value and Cost of Ownership'), a project sponsored by the EU Framework Programme Horizon 2020, MSCA-RISE-2014: Marie Skłodowska-Curie Research and Innovation Staff Exchange (RISE) (grant agreement number 645733 - Sustain-Owner - H2020-MSCA-RISE-2014). 


\title{
A dynamic opportunistic maintenance model to maximize energy-based availability while reducing the life cycle cost of Wind Farms
}

\author{
A. Erguido ${ }^{\mathrm{a}, \mathrm{b}, * *}$, A. Crespo Márquez ${ }^{\mathrm{b}, *}$, E. Castellano ${ }^{\mathrm{c}}$, J.F. Gómez Fernández $^{\mathrm{b}}$ \\ ${ }^{a}$ IK4-Ikerlan Technology Research Centre, Operations and Maintenance Technologies Area, 20500 Gipuzkoa, Spain \\ $5{ }^{b}$ Departamento de Organización Industrial y Gestión de Empresas I, Escuela Superior de Ingenieros, Universidad de Sevilla, \\ Camino de los Descubrimientos s/n, 41092 Sevilla, España \\ ${ }^{c}$ MIK Research Centre, Mondragon University, 20560 Gipuzkoa, Spain
}

\begin{abstract}
Operations and maintenance costs of the wind power generation systems can be reduced through the implementation of opportunistic maintenance policies at suitable indenture and maintenance levels. These maintenance policies take advantage of the economic dependence among the wind turbines and their systems, performing preventive maintenance tasks in running systems when some other maintenance tasks have to be undertaken in the wind farm. The existing opportunistic maintenance models for the wind energy sector follow a static decision making process, regardless of the operational and environmental context. At the same time, on some occasions policies do not refer to practical indenture and maintenance levels. In this paper, a maintenance policy based on variable reliability thresholds is presented. This dynamic nature of the reliability thresholds, which vary according to the weather conditions, provides flexibility to the decision making process. Within the presented model, multi-level maintenance, capacity constraints and multiple failure modes per system have been considered. A comparative study, based on real operation, maintenance and weather data, demonstrates that the dynamic opportunistic maintenance policy significantly outperforms traditional corrective and static opportunistic maintenance strategies, both in terms of the overall wind farm energy production and the Life Cycle Cost.
\end{abstract}

Keywords: Opportunistic maintenance model, Dynamic reliability thresholds, Life Cycle Cost, Wind energy, Weather conditions

\section{Introduction}

The growing importance of renewable energy in terms of installed capacity and technological advances has been remarkable during the last years. This growth has been particularly notorious within the wind energy sector, which occupies a leading position among renewable energies [1]. Furthermore, the sector has not only suffered a great development for the last two decades but it is expected to continue its expansion during the following years, being firmly reinforced by the main World Powers energy plans [2].

Along with this progress new challenges have arisen, especially in terms of new technologies' reliability [3] and logistics associated to wind farms' (WF) maintenance [4]. Moreover, due to the trend of WFs' location shift towards offshore sites [5, 6], to deal with these challenges is getting even more difficult. As a result, operations and maintenance costs can rise to a $32 \%$ or a $12-30 \%$ of the total life cycle cost (LCC) in offshore or in onshore WFs respectively [7, [5].

\footnotetext{
*Corresponding author, Tel.: +34954487215.

** Principal corresponding author, Tel.: +34 943712400 .

Email addresses: aerguido@ikerlan.es (A. Erguido), adolfo@etsi.us.es (A. Crespo Márquez), ecastellano@mondragon.edu (E. Castellano), juan.gomez@iies.es (J.F. Gómez Fernández)
} 
Table 1: Nomenclature and Acronyms definition

\begin{tabular}{|c|c|c|c|}
\hline \multicolumn{4}{|c|}{ Nomenclature } \\
\hline \multirow{2}{*}{$\begin{array}{l}L C C \\
W F\end{array}$} & \multirow{2}{*}{ Life Cycle Cost } & \multirow[t]{2}{*}{$w_{i k}$} & \multirow{2}{*}{$\begin{array}{l}\text { Weight that determines reactivity of } S R T_{i k j} \\
\text { and } D R T_{i k} \text { to wind speed }\end{array}$} \\
\hline & & & \\
\hline \multirow{2}{*}{$W T$} & Wind Farm & $K$ & Number of FM considered for each system \\
\hline & Failure Mode & $J$ & \multirow{2}{*}{$\begin{array}{l}\text { Levels of PM types considered for each FM } \\
\text { Generalized Renewal Process }\end{array}$} \\
\hline$F M$ & \multirow{2}{*}{ Operations and Maintenance } & $G R P$ & \\
\hline$O \& M$ & & \multirow{2}{*}{$V A_{\text {hikt }}$} & \multirow{2}{*}{$\begin{array}{l}\text { Virtual age associated to FM } k \text { in system } i \\
\text { in WT } h \text { in period } t\end{array}$} \\
\hline$C M$ & Corrective Maintenance & & \\
\hline & Preventive Maintenance & \multirow{2}{*}{$\alpha_{i k}$} & \multirow{2}{*}{ Weibull scale parameter of FM $k$ of system $i$} \\
\hline$C B M$ & Condition Based Maintenance & & \\
\hline$C M S$ & Condition Monitoring System & $\beta_{i k}$ & $\begin{array}{l}\text { Weibull shape parameter of FM } k \text { of system } \\
i\end{array}$ \\
\hline$T T F$ & Time To Failure & \multirow{2}{*}{$q_{i k j}^{p r}$} & \multirow{2}{*}{$\begin{array}{l}\text { Restoration factor of } j \text { PM level on system } i \\
\text { for FM } k\end{array}$} \\
\hline$M T$ & Maintenance Team & & \\
\hline$v_{t}$ & Average wind speed in period $t$ & \multirow{2}{*}{$q_{i k}^{c}$} & \multirow{3}{*}{$\begin{array}{l}\text { Restoration factor of CM on system } i \text { for } \\
\text { FM } k\end{array}$} \\
\hline$v^{i}$ & Cut in wind speed & & \\
\hline$v^{o}$ & Cut out wind speed & & \\
\hline \multirow{2}{*}{$v^{r}$} & \multirow{2}{*}{$\begin{array}{l}\text { Wind speed at which Rated Power is } \\
\text { obtained }\end{array}$} & $N T$ & Number of Mis \\
\hline & & $C$ & Capacity of each MT (in hours) \\
\hline$G P_{t}$ & Generated Power in period $t$ & $c^{n a}$ & cost of No Availability or opportunity cost \\
\hline \multirow{2}{*}{$R_{i k}(V A)$} & Rated Power of the WT & $c^{p}$ & Penalty cost due to unplanned maintenance \\
\hline & Reliability of system i and FM k at virtual & $c_{i k}^{c}$ & $\begin{array}{l}\text { Cost of tools and materials needed for } \\
\text { performing CM of FM } k \text { in system } i\end{array}$ \\
\hline$S R T_{i k j}$ & Fixed Reliability Threshold for applying & $c_{i k j}^{p r}$ & $\begin{array}{l}\text { Cost of tools and materials needed for } \\
\text { performing PM } j \text { of FM } k \text { in system } i\end{array}$ \\
\hline & FM $k$ & $c^{\text {team }}$ & Cost of MT \\
\hline & & $c^{e t}$ & Extra time cost \\
\hline$S \Pi I_{i h}$ & system Rellabilly inresnord in period $t$ ior & $N T^{\max }$ & Maximum number of MTs \\
\hline & and FM $k$. & $N T^{c}$ & Number of MTs working on CM \\
\hline & Fixed Disn & $c^{\text {disp }}$ & cost of maintenance dispatch \\
\hline$D \cap \perp_{i k}$ & Disnatch Bolighility Throshld in pori & $m_{i k}^{c}$ & Maintainability of CM for FM $k$ in system $i$ \\
\hline $\begin{array}{l}D K 1_{i k t} \\
V\end{array}$ & Dispatch Reliability Threshold in period $t$ & $m_{i k}^{p r}$ & Maintainability of PM for FM $k$ in system $i$ \\
\hline$v$ & roliability throch & $O T$ & Total operating time \\
\hline & & $D^{t}$ & Required WF time-based availability \\
\hline$p$ & Periods of time considered for wind speed & $D^{o}$ & Required WF energy-based availability \\
\hline & rorecasting & $T$ & Maximum iteration periods \\
\hline
\end{tabular}

Within this context, asset management acquires high relevance in the sector since it is crucial to search optimal maintenance strategies that allow to improve wind turbines' (WT) reliability and to reduce maintenance cost while raising availability [8, 9]. In spite of its importance, asset management strategies are not optimised in practice nowadays, being corrective maintenance (CM) and time-based minor preventive maintenance (PM) such as routing checks for minimizing degradation effects [10], the most applied maintenance strategies [11].

In addition to these two maintenance policies, Condition Based Maintenance (CBM), enhanced by the several Condition Monitoring Systems (CMS) available for wind energy installations [12, 13, is the third maintenance method currently applied to the wind power systems [11]. In fact, based on their ability to prevent failures [14], CBM strategies have been proved to be cost effective [15, 16] and have been widely researched [17, 18].

Nevertheless, maintenance strategies based uniquely on WTs' health condition monitoring do not take into account that the WTs are multi-component systems composed by a number of subsystems, with dependencies among them that directly affect to the adequacy of the maintenance strategies [19, 20]. According 
to Nicolai and Dekker [21] these dependencies can be classified as: economic, when performing maintenance activities in different systems simultaneously have different economic consequences than implementing them individually [22]; structural, when a maintenance activity in a system implies performing further actions in other systems [23]; and stochastic, when the risk of failure of two different systems is not independent [24].

When any of the mentioned dependencies exist among subsystems, the optimal maintenance strategies are not those that consider the subsystems separately in the maintenance decision process [p. 479, 25]:

"Obviously, the optimal maintenance action for a given subsystem at any time point depends on the states of all subsystems in the system: the failure of one subsystem results in the possible opportunity to undertake maintenance on other subsystems (opportunistic maintenance)."

In such circumstances, both group maintenance policies and opportunistic maintenance policies are the most suitable maintenance policies, and thus, the most studied ones [19]. On the one hand, group maintenance strategies establish different groups of systems that will undergo maintenance activities attending to the number of failures suffered by the systems, their age or their operation time [26, 27]. However, group maintenance policy is especially cost effective when disassemble and reassembly costs are high [25], which particularly the case in the wind energy sector. On the other hand, opportunistic maintenance policy takes advantage of short term circumstances, performing maintenance in non-failed systems when a failure has already happened in another one; making the maintenance decision according to different thresholds regarding systems' age, reliability or health condition. Several models have demonstrated the suitability of opportunistic maintenance policy in diverse sectors following varied strategies, such as age limits [28, 29], combined failure distribution of the systems [30] or accumulated operated periods of the systems [19].

Although opportunistic maintenance policies have not been traditionally implemented in the wind power systems [31], more recently some authors have studied and demonstrated their suitability in the sector [32, 31, 20, 11, 33, 34, 35, 36]; mainly due to the positive economic dependence among WTs [33]. Furthermore, they allow handling some of the main conflicting objectives concerning the decision making process of the wind energy sector: the maximization of revenue, power and reliability and the minimization of operations and maintenance costs [37].

\subsection{Previous research}

According to the reviewed opportunistic maintenance models for the wind energy sector (see Table 2), Besnard et al. [32] demonstrate that it is possible to reduce the maintenance cost and the opportunity cost due to failures by taking advantage of both low wind speed periods and the dispatches for CM in order to perform some prearranged PM.

Tian et al. [31] focus their research on developing an opportunistic maintenance policy based on the condition monitoring data. Aided by this data, the authors identify the useful remaining life of the systems and they calculate the WT's reliability. So, if the reliability of the WT does not surpass a determined threshold, systems within the WT are replaced.

Ding and Tian [20] propose an opportunistic maintenance model where both imperfect and perfect maintenance levels are considered. This is, systems will not always return to a status as good as new after a repair (the reader is addressed to [38] for further information). In this research, the authors set two different age thresholds for each system, which are based on their Mean Time To Failure (MTTF), in order to make the maintenance decision. The same authors extended their research in Ding and Tian [11] considering different age thresholds for systems belonging to failed and running WTs.

The main focus of the research performed by Sarker and Faiz [35] is to find an opportunistic maintenance strategy that optimises maintenance cost following a multilevel preventive maintenance policy. With this purpose the authors establish several age thresholds for the systems, which determine the PM activities to be performed.

Atashgar and Abdollahzadeh [34] go a step further as they find multi-objective optimal maintenance strategies for minimizing both maintenance cost and loss of production in WFs with redundant WTs. Within this research the WTs are grouped into blocks and opportunistic repairs are performed to WTs of the same block, according to the reliability thresholds associated to perfect or imperfect maintenance. 


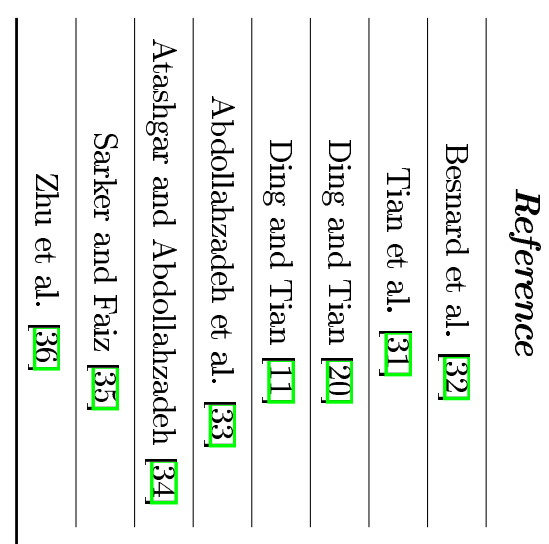

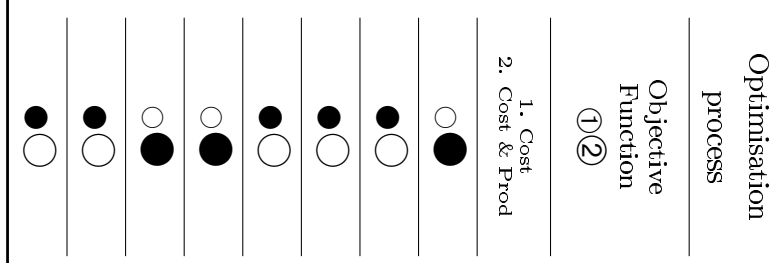

๖

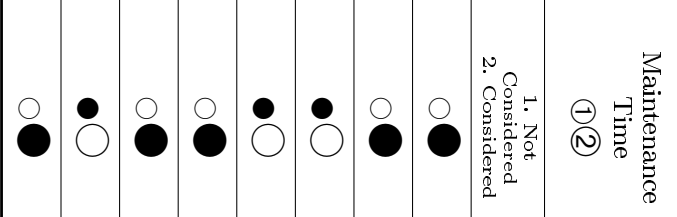

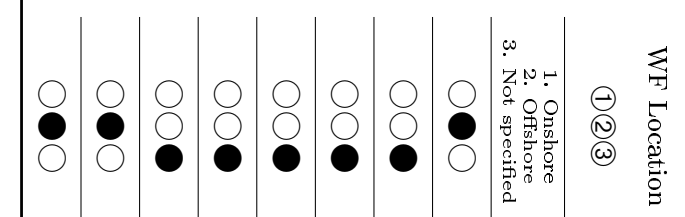

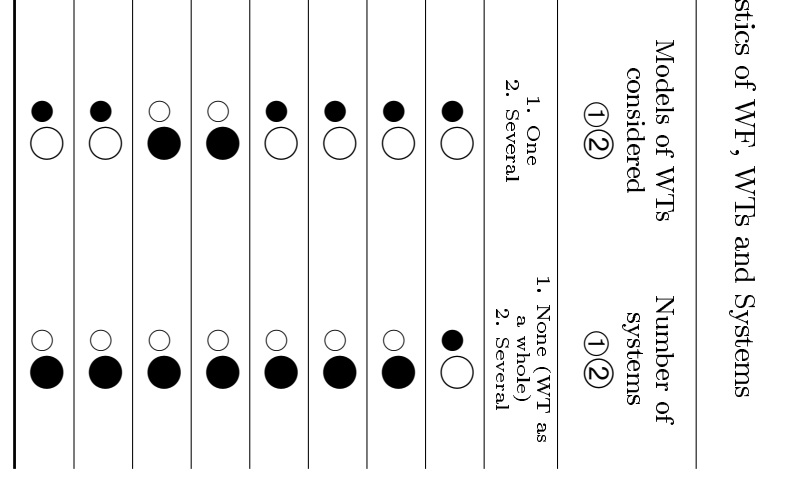

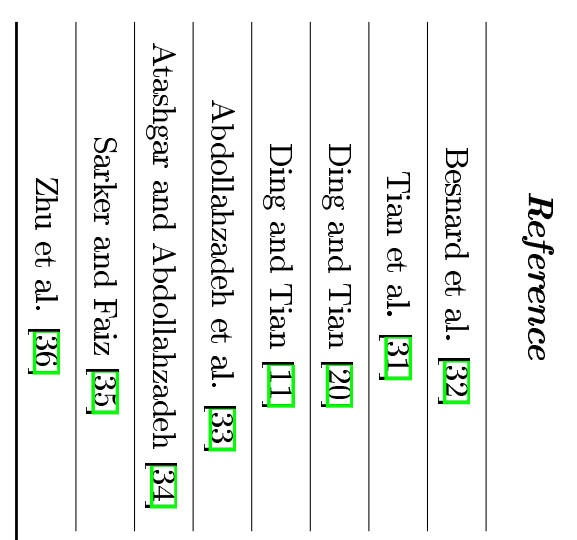

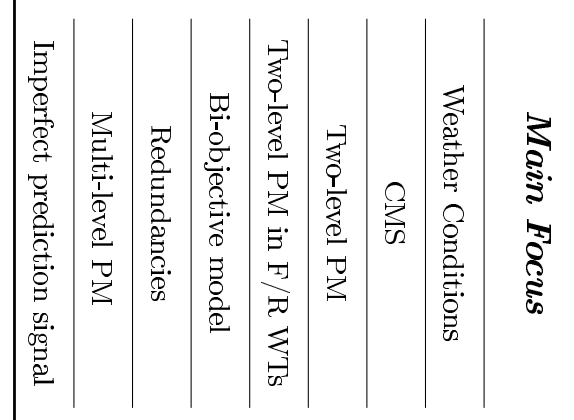

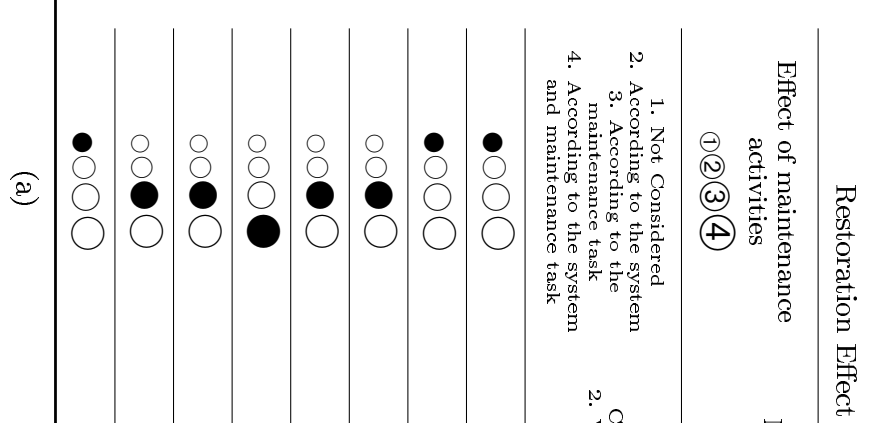

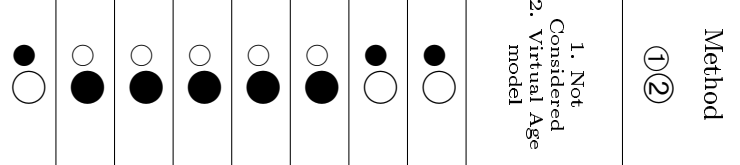

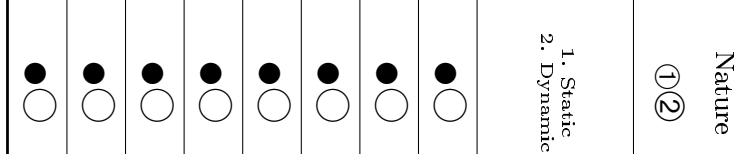

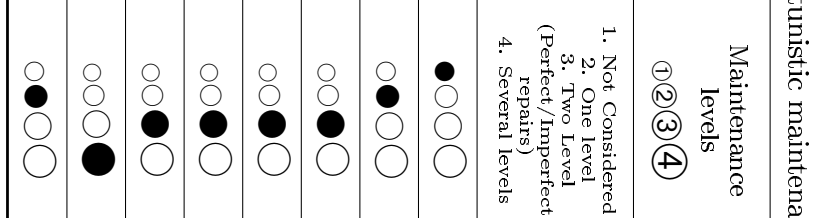

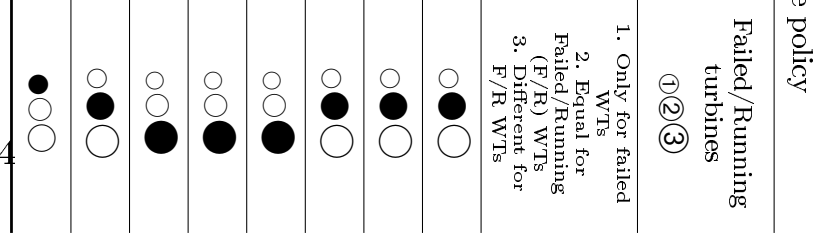


In Abdollahzadeh et al. [33], reliability thresholds that determine optimal maintenance activities are set for each component. Both in [33] and [34], maintenance teams (MT) can be preventively dispatched to the WF, instead of having to wait for a failure to happen.

Finally, Zhu et al. [36] study three different maintenance strategies for an offshore WF: periodic routine, reactive maintenance and opportunistic maintenance. In this research each system can only have a failure mode (FM), which can be either hard or soft according to the consequences. Moreover, in this research the impact of the CMS accuracy on opportunistic maintenance is also analysed.

\subsection{Proposed approach}

It is remarkable that the reviewed researches present static opportunistic maintenance policies that base the decision making process on fixed age, reliability or health thresholds. However, WTs operate under non-stationary conditions that highly condition the repair jobs [39, 40, 41]. So, ideally, the maintenance models should be able to adequately fit the decision making process to the conditions under which the WTs are operating at each time.

In order to deal with this challenge, a dynamic opportunistic maintenance model is presented in this paper. This model adjusts the decision making process according to the weather conditions, pursuing a double objective: 1) the optimisation of the total LCC due to maintenance and 2) the improvement of the WF energy-based availability.

With this purpose, the decision making process is determined by variable reliability thresholds, that change according to the wind speed conditions; fostering the performance of maintenance activities during low wind speed periods and hindering them during high wind speed periods. This dynamic nature, in addition to lead to a better performance of the maintenance strategies both in terms of energy-based availability and LCC, will also allow handling some of the most conflicting factors that appear in the wind power industry [37]:

1. Maximization of revenue and power while maximization of reliability [37].

2. MTs' safety while maintenance performance [10].

3. Minimization of the opportunity cost [42, 43, 44].

4. Improvement of reliability within high velocity wind periods [41].

In order to ensure a realistic approach of the model, several constraints have been included in the study, such as capacity limitations due to the available MTs and systems' maintainability. Furthermore, several FMs are considered per system, bearing their different impact on cost and availability. In fact, although the different FMs within each system directly condition the WT's performance and hence, the resources deployed in the maintenance strategy [45], in the reviewed opportunistic maintenance models only a FM is considered per system.

Finally, in order to prove the suitability of the model for establishing the adequate maintenance strategy, an agent-based simulation has been developed, taking advantage of the ability of simulation techniques to handle the stochastic nature of the sector [33]. The simulation results have been obtained from real operational and reliability data about WFs located in the north of Spain, provided by a leading company in the sector. Likewise, in order to search as realistic scenarios as possible, the simulation has also been fed with real wind data, according to the WF location.

The paper is organized as follows: in section 2 the problem is defined and the presented dynamic opportunistic maintenance policy is explained and analytically derived; in section 3 the simulation process is explained; in section 4 computational results are shown and discussed for a specific case study, comparing both traditional and presented approaches; finally, in section 5, concluding remarks are presented and future research lines are established.

\section{Problem definition and model description}

\subsection{Problem definition}

The WF consists of $H$ WTs of similar characteristics that have $N$ critical systems connected in series. Each system might fail in $k$ different FMs, classified according to their severity $(k=1,2, \ldots, K)$. Consequently, 
after a failure, corresponding $k \mathrm{CM}$ will be performed. Likewise, systems can also undergo different PM levels associated to the different FMs, prior to their occurrence $(j=1,2, \ldots, J)$.

Generally, the repairs return the systems to an operational condition worse than the new one but better than just before the maintenance task is performed. This concept leads to a classification of maintenance as perfect or imperfect, according to the ability of each maintenance activity to restore the system [38]. Accordingly, in this work both perfect and imperfect repairs have been considered, being $j=J$ a perfect repair and $j=1$ the most imperfect repair.

Among the several methods that treat the restoration effect of maintenance (see [38]), in this work the Generalized Renewal Process (GRP) proposed by Yañez et al. [46] is used. This method has been specifically utilised in the presented model due to its flexibility for modelling both the behaviour of the systems before failures and the quality of repairs during the different life stages of the systems. To do so, GRP considers a $q_{i j}$ rejuvenation parameter [0,1] associated to the efficiency of the restoration effect of the maintenance activity $j$ on the system $i$ ( $q=0$ for the most imperfect maintenance and $q=1$ for perfect maintenance). Consequently, after a maintenance activity $j$, Eq1 is followed to update the virtual age of the system $i$ (the reader is addressed to [46] for further information). Then, in order to identify systems' reliability after an imperfect repair, failure probability distribution conditioned to the survival of the new virtual age is calculated in Eq2 (adopted from [46]):

$$
V A_{i}^{\text {new }}=V A_{i}^{\text {old }}\left(1-q_{i j}\right)
$$

$$
F\left(t \mid V A_{i}^{\text {new }}\right)=P\left[T_{i j} \leq t \mid T_{i j}>V A_{i}^{\text {new }}\right]=\frac{F(t)-F\left(V A_{i}^{\text {new }}\right)}{1-F\left(V A_{i}^{\text {new }}\right)}
$$

In the wind energy sector, Weibull and Exponential distributions have been respectively utilised for modelling the reliability of mechanical and electrical systems [47. Since Exponential distribution is also contemplated by Weibull distribution as a particular case, Eq2 is particularized ad hoc for Weibull distribution in Eq 3 , according to the scale $\left(\alpha_{i k}\right)$ and shape parameters $\left(\beta_{i k}\right)$ that define the Weibull distribution for each FM $k$ of system $i$ (see [33]):

$R\left(t \mid V A_{h i k}^{\text {new }}\right)=1-F\left(t \mid V A_{h i k}^{\text {new }}\right)=\exp \left[\left(\frac{V A_{h i k}^{\text {new }}}{\alpha_{i k}}\right)^{\beta_{i k}}-\left(\frac{t}{\alpha_{i k}}\right)^{\beta_{i k}}\right]$

Finally, every failure occurrence or PM involves some fixed and variable maintenance costs that have to be considered in the model. Every maintenance activity implies dispatching a MT to the WF, which involves a relevant $\operatorname{cost}\left(c^{d i s p}\right)$. Likewise, each maintenance task will require a material cost $\left(c_{i k}^{c}, c_{i k}^{p r}\right)$ and a time to repair $\left(m_{i k}^{c}, m_{i k}^{p r}\right)$. However, since in the wind energy sector there are some failures caused by sensors' false alarms, each system has been provided with a FM $k=1$ that has an impact in terms of availability, but not in terms of material, human resources nor dispatch cost. The time to repair is the source of the opportunity and penalty costs $\left(c^{n a}, c^{p}\right)$ and the human resources' need, which can be either internal or external. According to internal resources a number of MTs are hired $\left(N T^{\max }\right)$ and are considered to be constant through the whole analysis. The MTs have a certain annual cost $\left(c^{\text {team }}\right)$ and capacity $(C)$. Finally, whereas when no own resources are available to perform required CM activities extra time $(E T)$ is externally hired at an extra cost $\left(c^{e t}\right)$, PM will only be performed with own resources.

\subsection{Dynamic opportunistic maintenance policy}

Two different maintenance decisions are considered within the presented dynamic opportunistic maintenance policy according to respective dynamic reliability thresholds: the MT dispatch to the WF, based on $D R T_{i k}$, and the PM decision, based on $S R T_{i k j}$. Accordingly, on the one hand, if the reliability of any FM $\left(R_{i k}(V A)\right)$ does not reach the $D R T_{i k}$, the decision of preventively dispatching a MT to the WF will 
be made, ensuring a minimum reliability for every system and FM. On the other hand, once the decision of dispatching a MT to the WF has been made -either preventively or correctively-, the imperfect PM decision is made according to $S R T_{i k j}$ (see Figures 1 and 2).

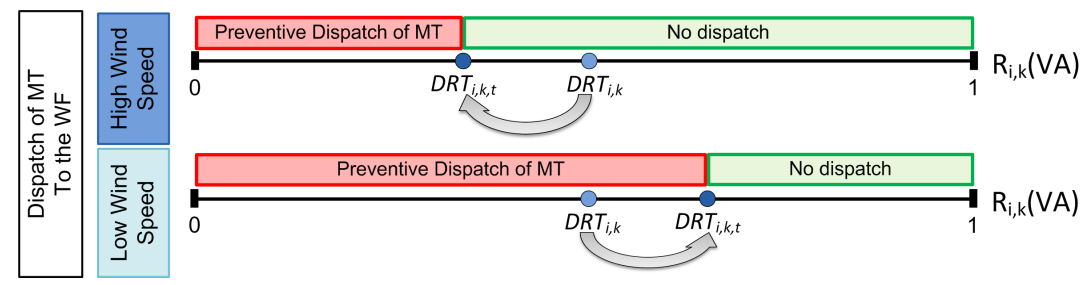

(a) Decision-making structure for the dispatch of the maintenance teams

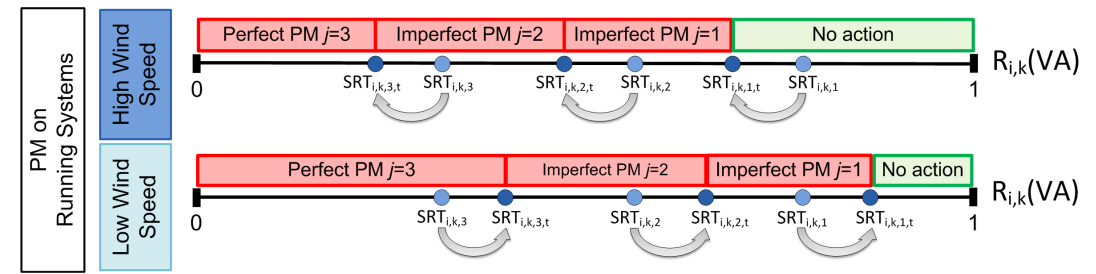

(b) Decision-making structure for performing PM. Example with 3 PM levels per FM

Figure 1: Decision-making structure for the dynamic opportunistic maintenance model

As stated, whereas in the reviewed researches these thresholds are static, in the presented model they are dynamic. Both $D R T_{i k}$ and $S R T_{i k j}$ will vary with regards to wind speed conditions according to Eq4 6 ; being increased in low wind speed periods and decreased in high speed periods. Thus, PM will be fostered during low wind periods and hindered during high wind speeds periods (see Figure 1). As shown in Eq4 6 the variation of the thresholds -and hence, the maintenance strategy- is determined by the following factors:

1. Wind speed threshold $(V)$ : during wind speed periods above this value, the reliability thresholds will decrease, hindering the PM activities; and on the contrary during low wind speed periods. Wind speed during the next $p$ periods of time is forecasted and compared to $V$ in order to determine if reliability thresholds should decrease or increase (Eq 6).

2. Generated power $\left(G P_{t}\right)$ and reactivity weight $\left(w_{i k}\right)$ : determine to which extent the reliability thresholds should be reactive to wind conditions. The gradient of both $D R T_{i k}$ and $S R T_{i k j}$ is proportional to the difference between the generated power at each time period $\left(G P_{t}\right)$ and the rated power of WTs $(R P)$.

$$
\begin{aligned}
& S R T_{i k j t}=S R T_{i k j}+\left(2 W_{t}-1\right) \cdot S R T_{i k j} \cdot w_{i k} \cdot\left(\frac{R P}{G P_{t}+R P \cdot W_{t}}\right)^{\left(2 W_{t}-1\right)} \\
& D R T_{i k t}=D R T_{i k}+\left(2 W_{t}-1\right) \cdot D R T_{i k} \cdot w_{i k} \cdot\left(\frac{R P}{G P_{t}+R P \cdot W_{t}}\right)^{\left(2 W_{t}-1\right)} \\
& W_{t}= \begin{cases}1 & \sum_{l=t}^{t+p} \frac{v_{l}}{p} \leq V \\
0 & \sum_{l=t}^{t+p} \frac{v_{l}}{p}>V\end{cases}
\end{aligned}
$$

It is not the aim of the dynamic opportunistic maintenance to eliminate the PM activities, but to plan them when weather conditions are more advantageous. Since WTs should be stopped during maintenance, downtime periods (time-based availability) will be similar in both dynamic and static maintenance strategies. However, energy losses will be reduced through dynamic opportunistic maintenance, maximizing WF's 
production and energy-based availability and minimizing opportunity cost derived from the unavailability periods. In other words, the WTs will be available during the most profitable periods. Likewise, as maintenance activities will be prone to be planned within low wind speed periods, safety of maintenance teams will also be improved [10].

Furthermore, on some occasions WFs must be stopped due to different reasons, such as for substation maintenance. Since no power can be generated during these periods, maintenance managers usually take the opportunity of performing PM. In order to consider such situations within the model, and help the manager on the maintenance decision to be made during these periods as well, they should be considered as no-wind periods $\left(\sum_{l=t}^{t+P} \frac{v_{l}}{p}=0\right)$, since no power can be generated. Consequently, according to the established maintenance policy, the thresholds will be increased during these periods, fostering PM.

\subsection{Mathematical model}

In this section the mathematical formulation of the dynamic opportunistic maintenance model is developed according to the maintenance process shown in Figure 2. To this aim, the standard approach of discretising the time in order to formulate stochastic programming models $(T=\{0,1,2, \ldots, T\})$ has been considered. Without loss of generality, some assumptions have been made for its formulation:

1. Degradation processes of the systems are considered independent from each other and they are associated to the operation time (ageing systems).

2. As commonly done in ageing systems, Increasing Failure Rate (IFR) is considered.

3. Installed WTs are the same model, composed by similar systems. Therefore, reliability distribution of the FMs of the systems is irrespective of the WT that contains them.

4. Reliability of the FMs follows the Weibull distribution, with scale parameter $\alpha$ and shape parameter $\beta$.

5. Maintenance activities should be finished during the period of time in which they are started.

6. A maintenance dispatch is considered per period of time, where several MTs can be dispatched.

7. The wake effect affection to WTs' production has been considered to be minimised during the WF layout design optimisation [48] and thus neglected.

8. PM is assumed to be less resource-consuming than CM since

(a) extra damages in other systems because of failures reduction;

(b) stock management can be planned in advance;

(c) resources can be allocated to maintenance tasks in a balanced way.

9. WF maintenance managers make decisions in discrete time and frequently [39].

The principal objective of the model is to minimize the LCC due to O\&M while providing the maximum WF energy-based availability. Accordingly, the optimal reliability thresholds that define the dynamic opportunistic maintenance policy $\left(S R T_{i k j t}, D R T_{i k t}\right)$, i.e. the decision variables of the model, should be found.

Table 3: Intermediate Binary variables utilised in the model

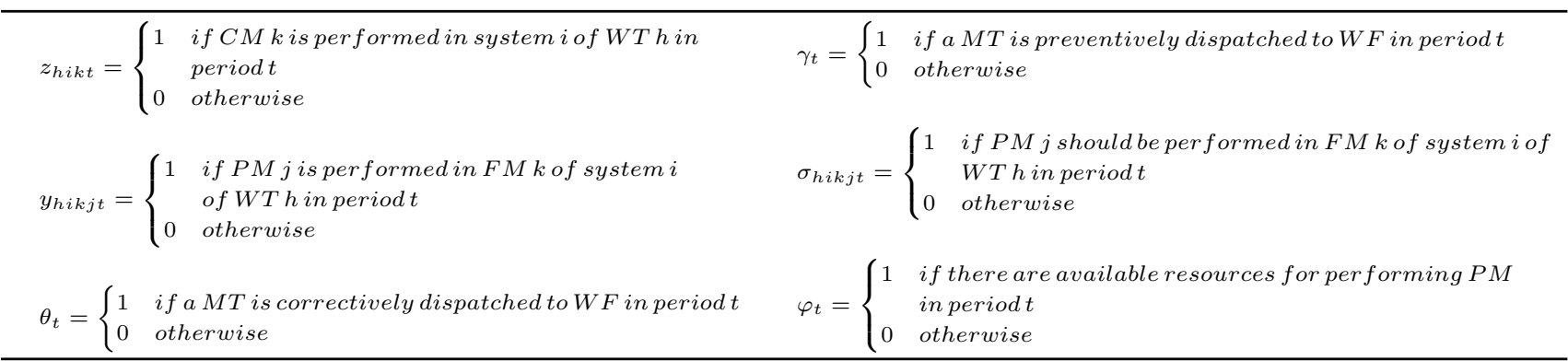




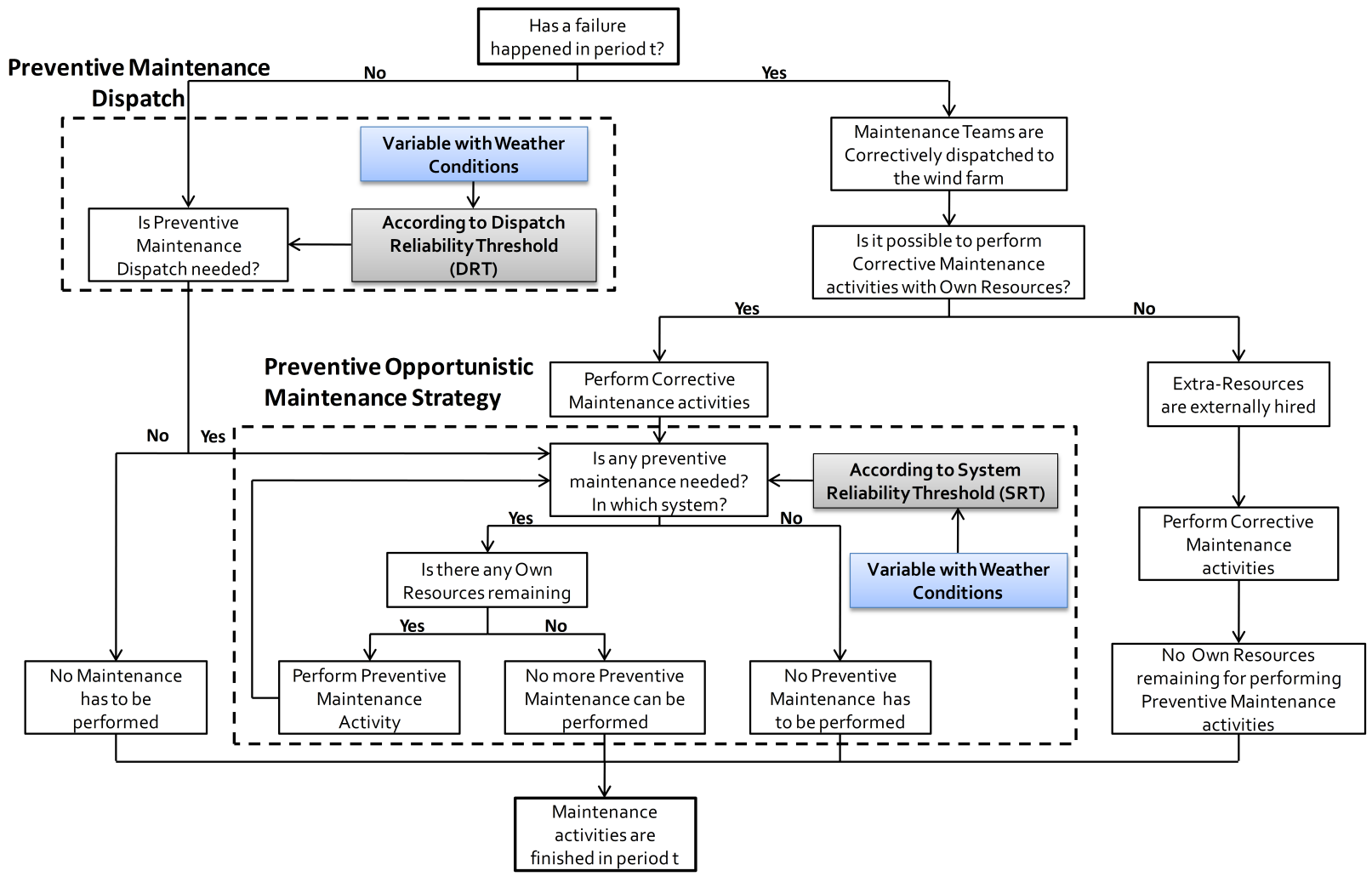

Figure 2: Flowchart of the Dynamic Opportunistic Maintenance Model

To this aim, the objective function (see Eq.7) of the model bears the main O\&M costs to be faced in a WF, related to the failure ocurrence $\left(z_{h i k t}\right)$ and the PM decision $\left.\left(y_{h i k j t}\right): 1\right)$ own and externally hired human resources needs, both in terms of own maintenance teams $\left(N T, c^{\text {team }}\right)$ and extra time needed $\left.\left(E T, c^{e t}\right) ; 2\right)$ dispatching of MTs to the WF $\left.\left(c^{\text {disp }}\right) ; 3\right)$ material and tools requirements $\left(c_{i k}^{c}, c_{i k j}^{p r}\right)$; and 4) production losses $\left(c^{n a}\right)$ and penalty costs $\left(c^{p}\right)$ due to WTs unavailability during maintenance, directly proportional to maintenance tasks duration $\left(m_{i k}^{c}, m_{i k j}^{p r}\right)$ and the lost power during maintenance $\left(G P_{t}\right)$. The cost of the imperfect maintenance has been defined as a function of the restoration factor $\left(q_{i k}^{c}, q_{i k, j}^{p r}\right)$ (as in [11]), as well as the maintainability. Due to the long term nature of the study the maintenance cost at each period $t$ has to be updated to present value according to an interest rate $\left(k_{a}\right)$ :

$$
\begin{gathered}
\min L C C\left(D R T_{i k t}, S R T_{i k j t}\right)=\left[\sum_{t} E T_{t} \cdot c^{e t}+\sum_{t} N T \cdot c^{t e a m}+\sum_{t}\left(\gamma_{t}+\theta_{t}\right) \cdot c^{d i s p}+\right. \\
\sum_{h} \sum_{i} \sum_{k \neq 1} \sum_{t} z_{h i k t} \cdot c_{i k}^{c} \cdot\left(q_{i k}^{c}\right)^{2}+\sum_{h} \sum_{i} \sum_{k} \sum_{t} z_{h i k t} \cdot m_{i k}^{c} \cdot\left(q_{i k}^{c}\right)^{2} \cdot G P_{t} \cdot\left(c^{n a}+c^{p}\right)+ \\
\left.\sum_{h} \sum_{i} \sum_{k} \sum_{j} \sum_{t} y_{h i k j t} \cdot\left(q_{i k j}^{p r}\right)^{2} \cdot\left(m_{i k j}^{p r} \cdot G P_{t} \cdot\left(c^{n a}+c^{p}\right)+c_{i k j}^{p r}\right)\right] \cdot\left(1+k_{a}\right)^{-t}
\end{gathered}
$$

The objective of maximizing WFs' energy-based availability -calculated attending to the lost power during maintenance tasks duration and total available power $\left(H \cdot \sum_{t} G P_{t}\right)$ - is ensured through the establishment of 
a minimum energy-based availability requirement (Eq 8). The time-based availability -calculated attending to the tasks duration and total operating time $(O T)$ - is also calculated through Eq 9 .

$$
\begin{aligned}
& H \cdot \sum_{t} G P_{t}-\left[\sum_{h} \sum_{i} \sum_{k} \sum_{t} m_{i k}^{c} \cdot z_{h i k t} \cdot\left(q_{i k}^{c}\right)^{2} \cdot G P_{t}\right. \\
& \frac{\left.+\sum_{h} \sum_{i} \sum_{k} \sum_{j} \sum_{t} m_{i k j}^{p r} \cdot y_{h i k j t} \cdot\left(q_{i k j}^{p r}\right)^{2} \cdot G P_{t}\right]}{H \cdot \sum_{t} G P_{t}} \geq D^{o}
\end{aligned}
$$

$$
\begin{array}{r}
O T-\left[\sum_{h} \sum_{i} \sum_{k} \sum_{j} \sum_{t} m_{i k j}^{p r} \cdot y_{h i k j t} \cdot\left(q_{i k j}^{p r}\right)^{2}\right. \\
\left.+\sum_{h} \sum_{i} \sum_{k} \sum_{t} m_{i k}^{c} \cdot z_{h i k t} \cdot\left(q_{i k}^{c}\right)^{2}\right]
\end{array}
$$

The generation of power is modelled regarding the average wind speed at each period. Power is only generated in wind speeds between cut in $\left(v^{i}\right)$ and cut out $\left(v^{o}\right)$ wind speeds, increasing non linearly until the wind speed in which the rated power $(R P)$ is reached $\left(v^{r}\right)$. The mathematical relationship has been defined as in Karki and Patel [49]:

$G P_{t}= \begin{cases}0, & 0 \leq v_{t}<v^{i} \\ R P \cdot\left(a+b \cdot v_{t}+c \cdot v_{t}^{2}\right) & v^{i} \leq v_{t}<v^{r} \\ R P & v^{r} \leq v_{t}<v^{o} \\ 0, & v^{o} \leq v_{t}\end{cases}$

where the parameters in Eq. 10 are obtained as follows [49]:

$$
\begin{aligned}
& a=\frac{1}{\left(v^{i}-v^{r}\right)^{2}}\left[v^{i}\left(v^{i}+v^{r}\right)-4 v^{i} v^{r}\left(\frac{v^{i}+v^{r}}{2 v^{r}}\right)^{3}\right] \\
& b=\frac{1}{\left(v^{i}-v^{r}\right)^{2}}\left[4\left(v^{i}+v^{r}\right)\left(\frac{v^{i}+v^{r}}{2 v^{r}}\right)^{3}-\left(3 v^{i}+v^{r}\right)\right] \\
& c=\frac{1}{\left(v^{i}-v^{r}\right)^{2}}\left[2-4\left(\frac{v^{i}+v^{r}}{2 v^{r}}\right)^{3}\right]
\end{aligned}
$$

As stated, the decision of preventively dispatching a MT to the WF relies on $D R T_{i k t}$, which varies according to the wind speed forecasting (see Eq 56 ) between $[0,1](\mathrm{Eq} 14)$. When the reliability of any FM of a system $\left(R_{i k}\right)$ does not reach its required threshold $\left(D R T_{i k t}\right)$, MTs are preventively dispatched to the WF (Eq 15). Likewise, if a failure happens in $t\left(z_{h i k t}=1\right)$, the dispatch of the MT is compulsory (Eq 16). Furthermore, dispatches of MTs are limited to one per period (Eq17), being able to send several teams in the same dispatch. 
$\gamma_{t}= \begin{cases}1 & R_{i k}\left(V A_{\text {hikt }}\right) \leq D R T_{i k t} \\ 0 & \text { otherwise }\end{cases}$

$\theta_{t}= \begin{cases}1 & \sum_{h} \sum_{i} \sum_{k \neq 1} z_{h i k t} \geq 1 \\ 0 & \text { otherwise }\end{cases}$

$\theta_{t}+\gamma_{t} \leq 1$

The decision of performing PM activities is based on $S R T_{i k j t}[0,1]$ (see Eq 46 18). When the reliability of a system does not reach the required reliability threshold (Eq.19) a system is susceptible of being preventively maintained; however, more conditions have to be met in order to perform PM (see Figure 2): 1) only the most comprehensive maintenance is performed, i.e. if both imperfect and perfect maintenance are needed, perfect maintenance will be performed (Eq 20); 2) a MT must have been previously dispatched to the WF (Eq21); 3) own human resources have to be available for performing PM (Eq 25 26); and 4) only a maintenance activity is performed at each time on the WT (Eq22).

$0 \leq S R T_{i k j t} \leq 1$

$\sigma_{\text {hikjt }}= \begin{cases}1 & R_{i k}\left(V A_{h i k t}\right) \leq S R T_{i k j t} \\ 0 & \text { otherwise }\end{cases}$

$y_{h i k j t} \leq \sigma_{h i k j t}-\sigma_{h i k(j+1) t}$

$y_{\text {hikjt }} \leq \theta_{t}+\gamma_{t}$

$\forall h \epsilon H, \forall i \epsilon I, \forall k \epsilon K, \forall j \epsilon J, \forall t \epsilon T$

$\sum_{i} \sum_{k} \sum_{j} y_{h i k j t}+\sum_{i} \sum_{k} z_{h i k t} \leq 1$

$\forall h \epsilon H, \forall t \epsilon T$

In fact, with regard to human resource limitations, some capacity constraints have been set (Eq 23 26). As shown in Figure 2 each CM must be performed, and if no resources are available, extra time $(E T)$ is externally hired at a higher cost (Eq 23). Eq24 ensures that no more than the maximum available MTs $\left(M T^{\max }\right)$ are used for CM at each time $\left(N T_{t}^{c} \in\left\{1,2, \ldots, N T^{\max }\right\}\right)$. Since PM can only be performed with own resources, Eq25 analyses if there are still own resources available after CM; and if so, PM is performed if needed (Eq26).

$\sum_{h} \sum_{i} \sum_{k \neq 1} z_{h i k t} \cdot m_{i k}^{c} \cdot\left(q_{i k}^{c}\right)^{2} \leq C \cdot N T_{t}^{c}+E T_{t}$ 
When PM or CM are performed $\left(y_{h i k j t}=1, z_{i k h t}=1\right)$, the system's virtual age associated to FM $k$ $\left(V A_{h i k t}\right)$ is reduced according to the restoration factor $\left(q_{i k j}^{p r}, q_{i k}^{c}\right)$. If no action is performed in a system during a period, the virtual age should be increased by a period (Eq,27).

$$
V A_{h i k t}=\left(V A_{h i k(t-1)}+1\right) \cdot\left(1-z_{h i k t} \cdot q_{i k}^{c}-y_{h i k j t} \cdot q_{i k j}^{p r}\right)
$$

\section{Simulation Process}

As shown in the analytical model, expected maintenance cost and production of the WF depend on the followed opportunistic maintenance policy, which is determined by the dynamic reliability thresholds. Therefore, in order to find profitable maintenance strategies, it is necessary to establish the correct set of thresholds $\left(S R T_{i k j}, D R T_{i k}\right)$ and their variation according to the forecasted wind conditions $\left(w_{i k}, V, p\right)$.

Due to the different stochastic processes that have to be considered within this complex system model, such as failure occurrence, repair processes, weather conditions, etc., it is hard to handle it analytically [11, 33. Therefore, although most part of the problem has been analytically derived, simulation techniques have been used to handle the many random scenarios that can appear for each set of reliability thresholds, as commonly done in other researches about the topic [35, 33. [34, 11, 31]. Particularly, an agent-based simulation has been developed due to its suitability to handle engineering problems with multi-agent systems [50]. The simulation process developed follows 6 different steps (see Figure 3).

Step 1. In the initialization of the simulation all the parameters needed for the simulation process are specified: the parameters needed for the dynamic reliability thresholds modelling, costs related to maintenance, reliability and maintainability distributions, number of MTs, maximum iteration period, etc.

Step 2. The simulation clock and virtual age of the FMs of the systems are updated, identifying their new reliability according to their age. Wind speed is also forecasted and reliability thresholds are accordingly updated.

Step 3. If any failure has happened, needed CM is applied and the virtual age of the system is updated. After the CM, the new time to failure $(T T F)$ is obtained through the Inverse Transform Technique [51], according to Eq.28 (adopted from [33]), in which $R$ is uniformly distributed between [0,1). If no failure occurs, whether a MT has to be preventively dispatched or not is also decided in this step.

$T T F_{h i k}=\alpha_{i k}\left[\left(\frac{V A_{h i k}}{\alpha_{i k}}\right)^{\beta_{i k}}-\ln (1-R)\right]^{\frac{1}{\beta_{i k}}}-V A_{h i k}$

Step 4. If a MT has been dispatched to the WF, PM decision is made according to the reliability thresholds. The virtual age and the new time to failure $\left(T T F_{h i k}\right)$ are updated for the maintained systems, according to Eq28. 


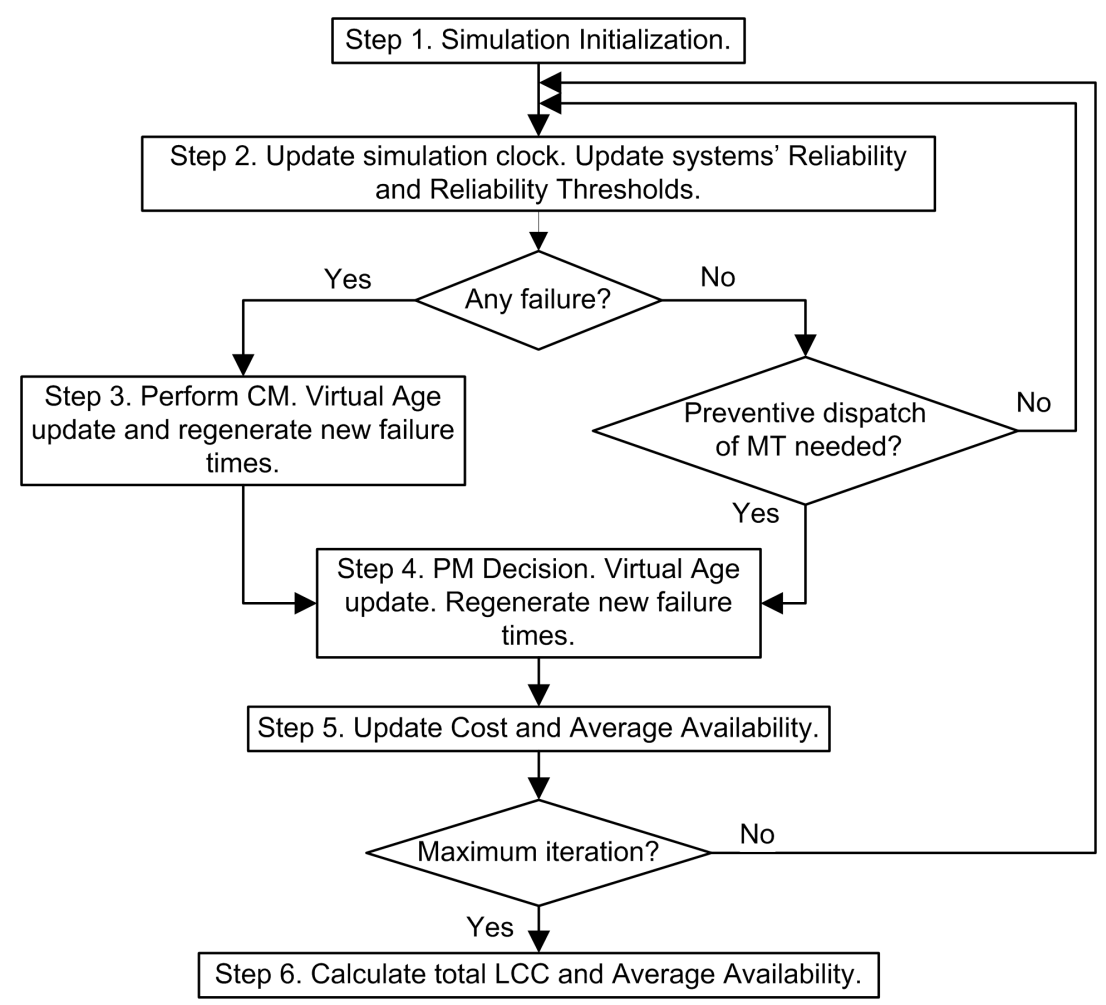

Figure 3: Simulation process for LCC and Energy-based availability evaluation

Step 5. LCC and energy-based availability are updated. If actual period is equal to the maximum iteration period, step 6 is followed. Otherwise, steps 2,3, 4 and 5 are repeated.

Step 6 . The total expected LCC and the average energy-based availability are calculated for the established opportunistic maintenance policy, $L C C=f\left[S R T_{i k j}, D R T_{i k}, w_{i k}, V, p\right]$.

\section{Case study \& Computational results}

An onshore application has been considered to test the efficiency of the dynamic opportunistic maintenance policy, since all the operation and reliability data provided by the wind energy company belonged to this type of WFs. The data available has been on more than 300 WTs over a time span of more than 12 years. These WTs are all the same-model and they are located in the North of Spain, working at similar operational conditions. Although this data is confidential and therefore no detailed numbers can be provided neither for the systems' reliability nor maintainability, the final results obtained are shown and explained in this section.

Three have been the strategies compared in the computational results shown below:

- Strategy 1. CM and minor PM are performed, as commonly done in the industry [11].

$$
L C C=f\left[S R T_{i k j}=0, D R T_{i k}=0, w_{i k}=0, V=0, p=0\right]
$$

- Strategy 2. CM and PM are performed, according to the static opportunistic maintenance policy established by the reliability thresholds. In this strategy, thresholds will not vary according to the wind conditions.

$$
L C C=f\left[S R T_{i k j}, D R T_{i k}, w_{i k}=0, V=0, p=0\right]
$$


- Strategy 3. CM and PM are performed, according to the presented dynamic opportunistic maintenance policy established by the reliability thresholds and their variation degree regarding the wind conditions.

$$
L C C=f\left[S R T_{i k j}, D R T_{i k} w_{i k}, V, p\right]
$$

315 Finally, a sensitivity analysis has been performed in order to discuss the most influential parameters within the model and to evaluate the different assumptions made. Despite the fact that the methodology has been applied to an Onshore WF, it could also be applied to an Offshore WF.

\subsection{WF profile}

A recently installed virtual WF that consists of $40 \mathrm{WTs}(H=40)$ of a rated power of 1,67 megawatt (MW) is considered. For each WT the 4 most critical systems are considered $(N=4)$, regarding both their reliability and the consequences of their failures, according to the data available for the study. These 4 systems are: gearbox, blades, pitch system and yaw system. For each system three independent FMs are analyzed $(K=3)$. As stated in Subsection 2.1, the $k=1 \mathrm{FM}$ does not have material requirements nor need of field-maintenance, since they are provoked by sensors' false alarms. The systems can also undergo two different PM levels $(J=2)$ associated to the FMs $(k=2,3)$, with a restoration factor associated to the maintenance routine $\left(q_{i k 1}^{p r}=0.75\right.$ and $\left.q_{i k 2}^{p r}=1\right)$ (see [11]).

The access cost to the WF is assumed to be $5000 €$, own resources $800 €$ /day per maintenance team, 2 maintenance teams, extra resources $250 € / \mathrm{hr}$ per maintenance team, the total opportunity cost $105 € / \mathrm{MWh}$, the penalization cost $35 € / \mathrm{MWh}$, the interest rate $5 \%$ and the lead time to the WF one hour. Finally, the cost for the materials and the maintainability of PM has been set a $30 \%$ lower than for CM. Further information about material cost for the WT under study can be found on Martin-Tretton et al. [52].

Since wind conditions are a key factor within the methodology, real wind data has been utilised in order to feed the simulation and obtain as much realistic scenarios as possible. The wind turbines cut-in, cut-out and rated speeds are assumed to be $3 \mathrm{~m} / \mathrm{s}, 25 \mathrm{~m} / \mathrm{s}$ and $13 \mathrm{~m} / \mathrm{s}$, respectively. Finally, daily wind average forecasting potential has been established to 5 periods $(p=5)$.

\subsection{Sensitivity analysis}

In this section the different parameters that condition the dynamic reliability thresholds, and hence, the presented dynamic opportunistic maintenance model, are discussed through a sensitivity analysis, considering the following base scenario: $S R T_{i 1 j}=0.0, S R T_{i 21}=0.8, S R T_{i 22}=0.4, S R T_{i 31}=0.8, S R T_{i 32}=$ $0.4, D R T_{i 2}=0.2, D R T_{i 3}=0.2, w_{i k}=0.5, V=2.0, p=5$.

Wind speed threshold $(V)$. The opportunistic maintenance strategy, both in terms of LCC and loss of production, shows a better performance when the wind speed threshold is established at low values. If higher values are established, the reactivity of the reliability thresholds is higher and maintenance is prone to be over-sized, increasing LCC and production losses. 


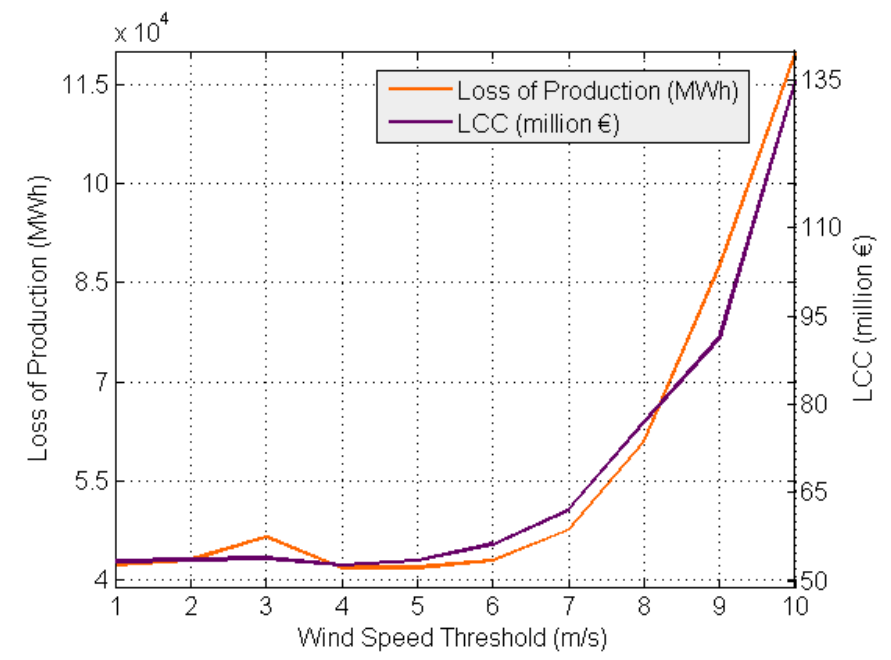

Figure 4: Expected LCC and Production Losses with different Wind Speed Thresholds

Number of periods for which average wind speed can be forecasted $(p)$. It is expected that if the average wind speed was forecasted for more periods of time, the performance of the maintenance strategy would show better results. However, the results show that the performance of the dynamic opportunistic maintenance model is quite regular from $p=3$ on.

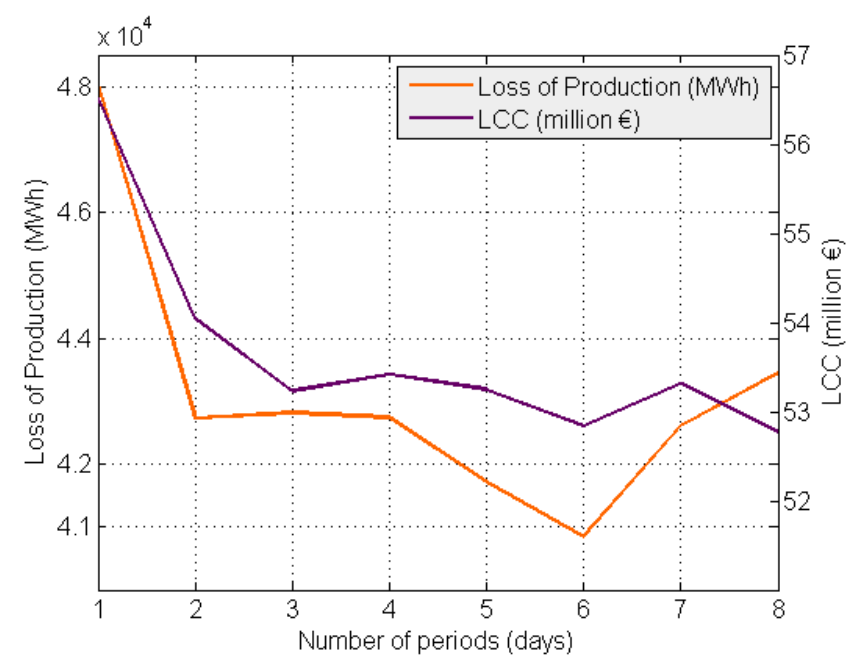

Figure 5: Sensitivity analysis according to predicted periods

Reactivity weight $\left(w_{i k}\right)$. It helps determining the variation degree of the thresholds associated to each FM according to wind and it is expected that the optimal value will be different for each FM. For the defined base scenario, the best performance, both according to LCC and Production losses, is found at $w_{i k}=0.5$. 


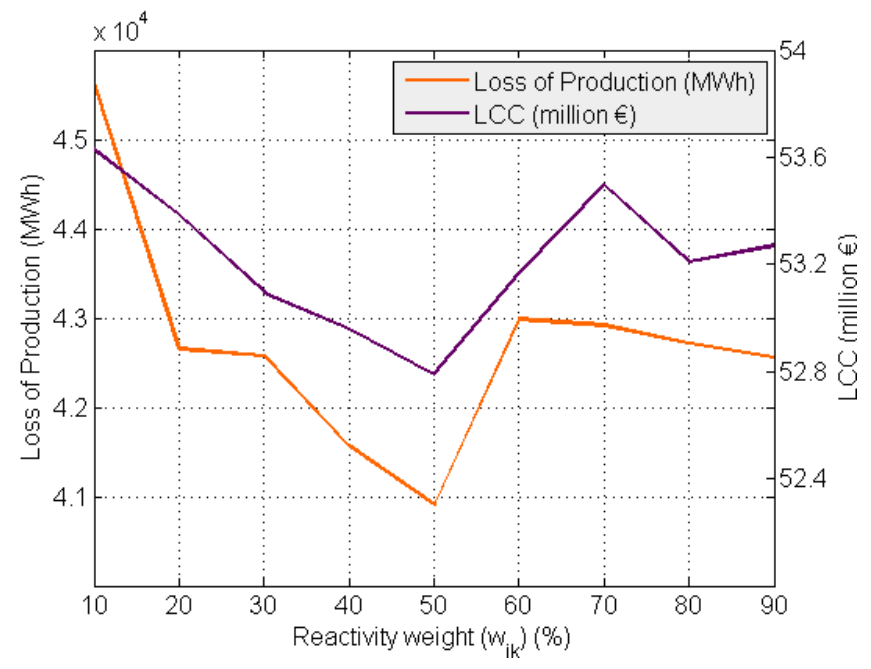

Figure 6: Expected LCC and Production Losses with different reactivities to wind $\left(w_{i k}\right)$

\subsection{Optimisation results and discussion}

The optimisation results presented in this section have been obtained through the OptQuest Engine, a commercial optimisation software developed by Fred Glover in OptTek Systems Inc. (Opttek Systems Inc. 2000) that has been proved to be robust and efficient on finding high-quality solutions [53]. The OptQuest Engine is based on scatter search and it also integrates successfully Tabu search, integer programming, and a procedure to configure and train neural networks for the optimisation of stochastic problems [54]. Especially, neural networks play an important role in order to avoid getting trapped in local minima, since they are able to remember good solutions and recombine them to guide the search towards the best solutions [55]. For further information about scatter search and the OptQuest Engine the reader is addressed to [56, 53., 57].

\begin{tabular}{|c|c|c|c|c|c|c|c|c|c|c|c|c|}
\hline & \multicolumn{3}{|c|}{ Gearbox } & \multicolumn{3}{|c|}{ Pitch } & \multicolumn{3}{|c|}{ Yaw } & \multicolumn{3}{|c|}{ Blades } \\
\hline & Dec. Var & Str. 2 & Str.3 & Dec. Var & Str.2 & Str. 3 & Dec. Var & Str.2 & Str.3 & Dec. Var & Str.2 & Str.3 \\
\hline \multirow{4}{*}{ FM1 } & $S R T_{11 j}$ & 0.0 & 0.0 & $S R T_{21 j}$ & 0.0 & 0.0 & $S R T_{41 j}$ & 0.0 & 0.0 & $S R T_{41 j}$ & 0.0 & 0.0 \\
\hline & $D R T_{11}$ & 0.0 & 0.0 & $D R T_{21}$ & 0.0 & 0.0 & $D R T_{31}$ & 0.0 & 0.0 & $D R T_{41}$ & 0.0 & 0.0 \\
\hline & $w_{11}$ & 0.0 & 0.0 & $w_{21}$ & 0.0 & 0.0 & $w_{31}$ & 0.0 & 0.0 & $w_{41}$ & 0.0 & 0.0 \\
\hline & V & 0.0 & 0.5 & V & 0.0 & 0.5 & V & 0.0 & 0.5 & V & 0.0 & 0.5 \\
\hline \multirow{5}{*}{ FM2 } & $S R T_{121}$ & 0.725 & 0.775 & $S R T_{221}$ & 0.9 & 0.925 & $S R T_{321}$ & 0.825 & 0.875 & $S R T_{421}$ & 0.775 & 0.825 \\
\hline & $S R T_{122}$ & 0.175 & 0.675 & $S R T_{222}$ & 0.175 & 0.225 & $S R T_{322}$ & 0.0 & 0.125 & $S R T_{422}$ & 0.675 & 0.6 \\
\hline & $D R T_{12}$ & 0.0 & 0.1 & $D R T_{22}$ & 0.175 & 0.15 & $D R T_{32}$ & 0.0 & 0.125 & $D R T_{42}$ & 0.675 & 0.6 \\
\hline & $w_{12}$ & 0.0 & 0.55 & $w_{22}$ & 0.0 & 0.2 & $w_{32}$ & 0.0 & 1.0 & $w_{42}$ & 0.0 & 0.6 \\
\hline & V & 0.0 & 0.5 & V & 0.0 & 0.5 & V & 0.0 & 0.5 & V & 0.0 & 0.5 \\
\hline \multirow{5}{*}{ FM3 } & $S R T_{131}$ & 0.725 & 0.75 & $S R T_{231}$ & 0.925 & 0.975 & $S R T_{331}$ & 0.9 & 0.90 & $S R T_{431}$ & 0.8 & 0.875 \\
\hline & $S R T_{132}$ & 0.3 & 0.325 & $S R T_{232}$ & 0.575 & 0.525 & $S R T_{332}$ & 0.6 & 0.55 & $S R T_{432}$ & 0.45 & 0.575 \\
\hline & $D R T_{13}$ & 0.175 & 0.3 & $D R T_{23}$ & 0.175 & 0.225 & $D R T_{33}$ & 0.475 & 0.5 & $D R T_{43}$ & 0.0 & 0.125 \\
\hline & $w_{13}$ & 0.0 & 0.35 & $w_{23}$ & 0.0 & 0.15 & $w_{33}$ & 0.0 & 0.7 & $w_{43}$ & 0.0 & 0.45 \\
\hline & V & 0.0 & 0.5 & V & 0.0 & 0.5 & $V$ & 0.0 & 0.5 & $V$ & 0.0 & 0.5 \\
\hline
\end{tabular}

Table 4: Optimised values for the Decision Variables

In order to compare the different strategies that are analyzed within the research, optimal values have been found for each one (see Table 4). The most remarkable results are: 
LCC \& Production Losses. Opportunistic maintenance strategies, both based on static and dynamic reliability thresholds, are proven to be economically effective compared to strategy 1 . In fact, according to the obtained results, opportunistic maintenance policies can reduce LCC by a $25 \%$ (see Table 5 and Figure 7). Likewise, optimisation results show that the use of the dynamic reliability thresholds (strategy 3 ) considerably outperforms the use of static reliability thresholds (strategy 2), minimizing the total production losses by almost a $27 \%$ and slightly improving the LCC as well. Furthermore, it is remarkable that the results in terms of production losses for strategy 3 are not achievable through strategy 2 . In fact, if the static reliability thresholds of strategy 2 were optimised for minimizing production losses instead of being optimised for minimizing the LCC, production losses would still be a $24,7 \%$ lower for strategy 3 than 2 , additionally increasing the LCC (see Table 5).

\begin{tabular}{llcc}
\hline \multicolumn{2}{c}{ Strategy } & LCC $(€)$ & Production Loss (MWh) \\
\hline \multirow{2}{*}{1} & & $67,544,964$ & 66,895 \\
\hline \multirow{2}{*}{2} & min LCC & $51,856,606$ & 50,239 \\
\cline { 2 - 4 } & min Pr. Loss & $52,982,284$ & 48,790 \\
\hline \multirow{2}{*}{3} & & $50,904,497$ & 36,743 \\
\hline
\end{tabular}

Table 5: Main optimisation results for each strategy

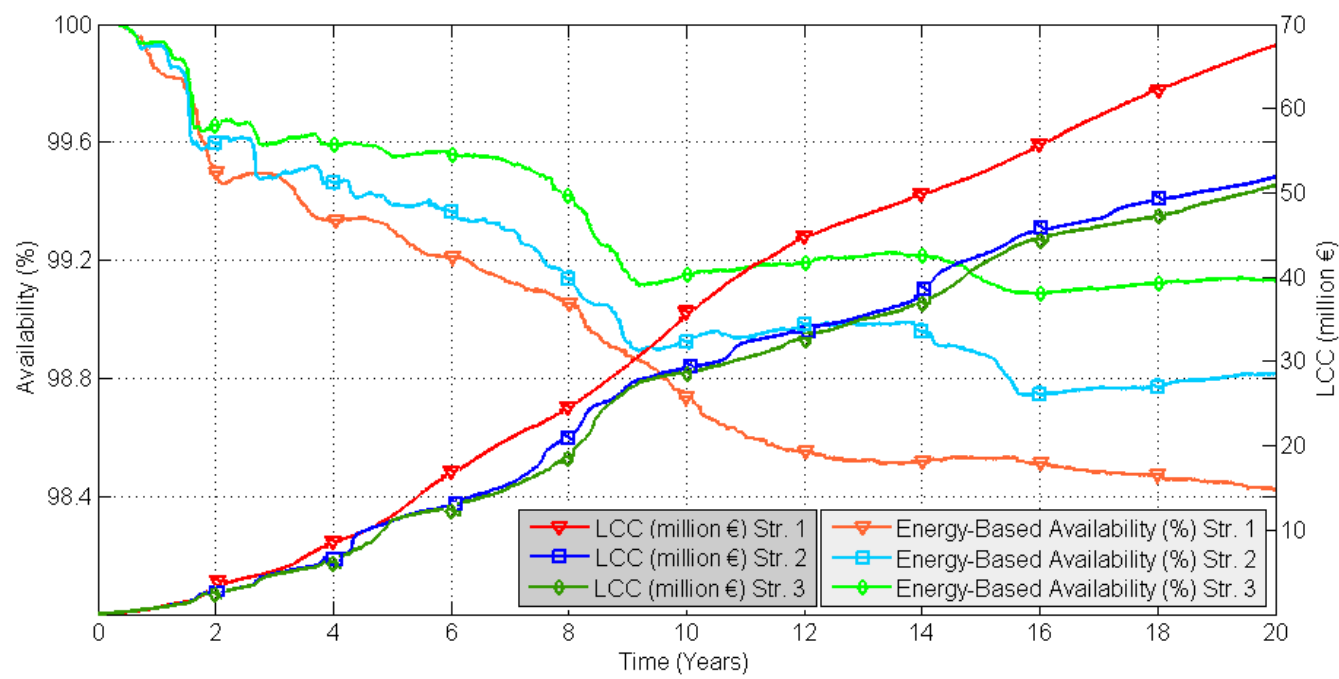

Figure 7: Strategies' performance comparison according to Energy-based Availability and LCC

This result is mainly due to the fact that WTs must be stopped during PM. Thus, even if more PM implies a better reliability, it is not the key to reduce the wind energy production losses. Consequently, if production losses are to be minimized, PM should be planned during low wind energy periods. It is at this point where the presented dynamic opportunistic maintenance, which systematically takes advantage of the low wind energy periods for performing maintenance, maximizes the total production and outperforms strategy 2, where the PM is planned regardless of the operational context of the WTs.

Energy-based availability \& Time-Based availability. If energy-based and time-based availability of strategies 2 and 3 are compared (Figure 8), it is observed that the dynamic reliability thresholds improve the overall energy-based availability. Whereas following strategy 2 implies that maintenance activities have almost the same impact in both time-based and energy-based availability, through the dynamic reliability thresholds, 
the impact of maintenance activities on the energy-based availability is minimized, reaching an energy-based availability over $99,1 \%$. This fact, along with the slight difference regarding LCC between strategies 2 and 3 , reaffirms that whereas the dynamic opportunistic maintenance policy does not reduce PM, it achieves to find more suitable maintenance opportunities with regards to the wind conditions than static opportunistic maintenance policy.

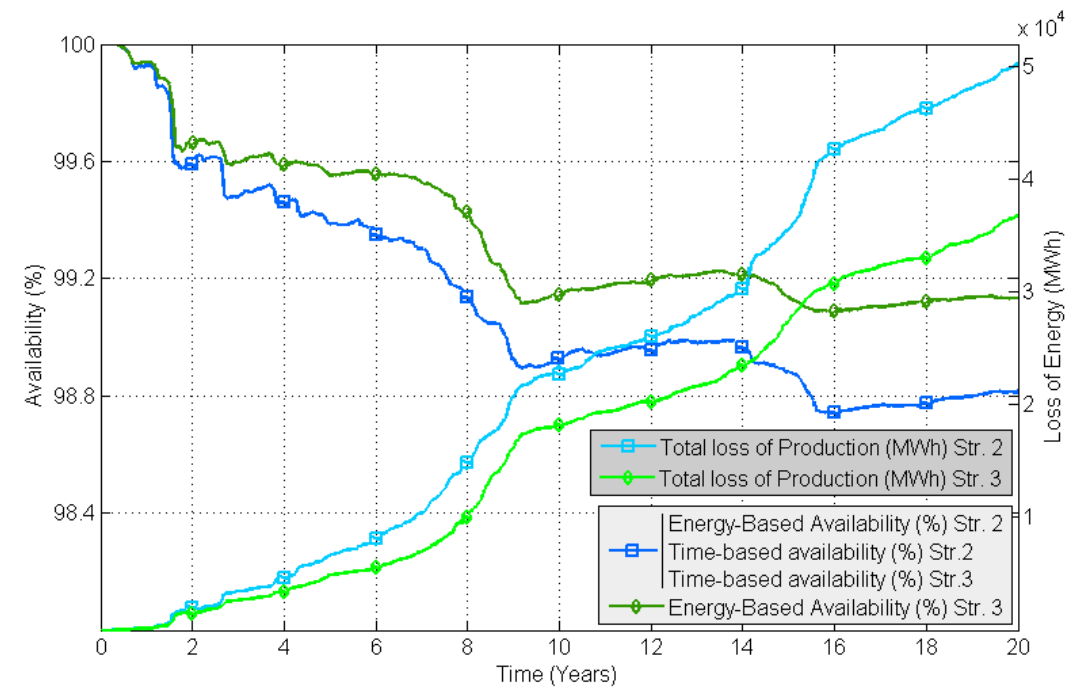

Figure 8: Strategies' performance comparison according to Energy-based and Time-based Availability

Wind speed during PM. As stated in Carlos et al. [10] optimal wind speeds for performing maintenance activities are those bellow $5 \mathrm{~m} / \mathrm{s}$, not only in terms of production, but also in terms of workers' safety. In fact, regarding workers' safety, maintenance in WTs is generally recommended to be performed under wind speeds bellow $12 \mathrm{~m} / \mathrm{s}$ [58]. As shown in Figure 9, following the strategy based on the dynamic reliability thresholds (strategy 3 ), nearly a $35 \%$ of the PM activities are performed under ideal conditions and a $97 \%$ under the recommended ones, whereas in strategy 2 , with the static reliability thresholds, these percentages decrease to a $22 \%$ and a $88 \%$, respectively. Moreover, according to power generation, these results show that whereas in strategy 2 more than a $10 \%$ of the PM activities are performed during maximum generation periods, in strategy 3 this figure falls to a $2 \%$. 


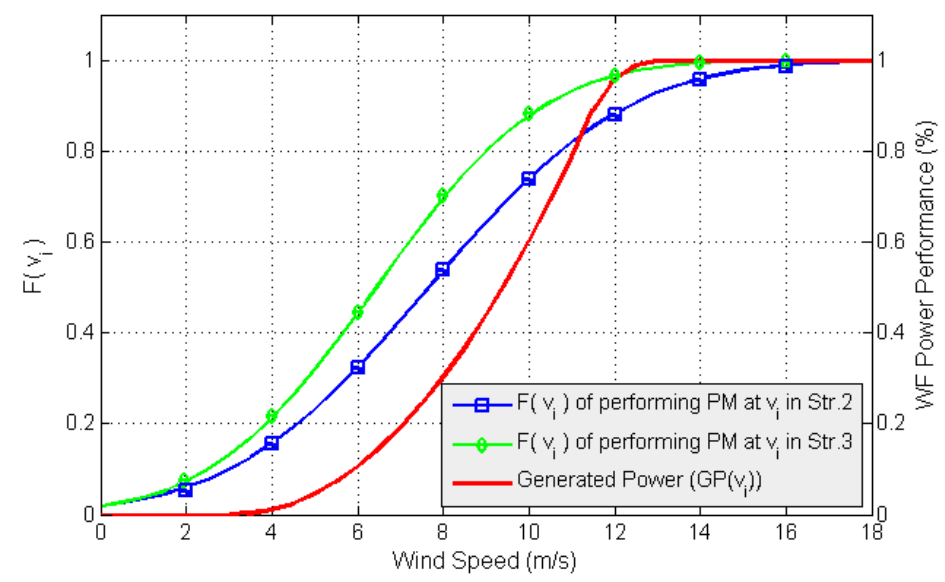

Figure 9: Wind speed at which PM is applied

Static and Dynamic opportunistic maintenance policies under stochastic wind speeds. The obtained results are based on real wind data according to the location of the wind farm. However, since wind predictions might be inaccurate and tendencies might change during the life cycle of the wind farm, the effect of wind speed variability both in LCC and loss of production has been analyzed (see Figures 10 and 11). To this aim, the wind data used to feed the simulation has been stochastically calculated at each time period based on the real wind data and a variability factor. According to the results shown in Figures 10 and 11, it can be noticed that the impact of wind speed variation in the static opportunistic maintenance is minor, since the reliability thresholds are optimised without considering the wind speed as an input. On the contrary, the wind speed variability directly affects the dynamic opportunistic maintenance, mostly in environments where the variability is higher than $60 \%$. However, strategy 3 still outperforms strategy 2 , excluding the most variable environment, where the results of strategies 2 and 3 are similar.

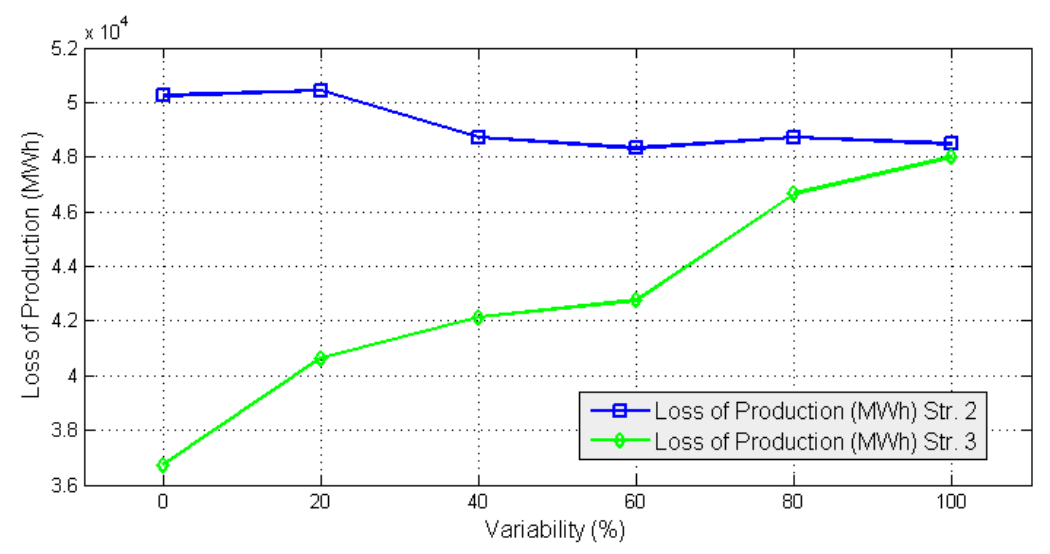

Figure 10: Loss of Production Variability 


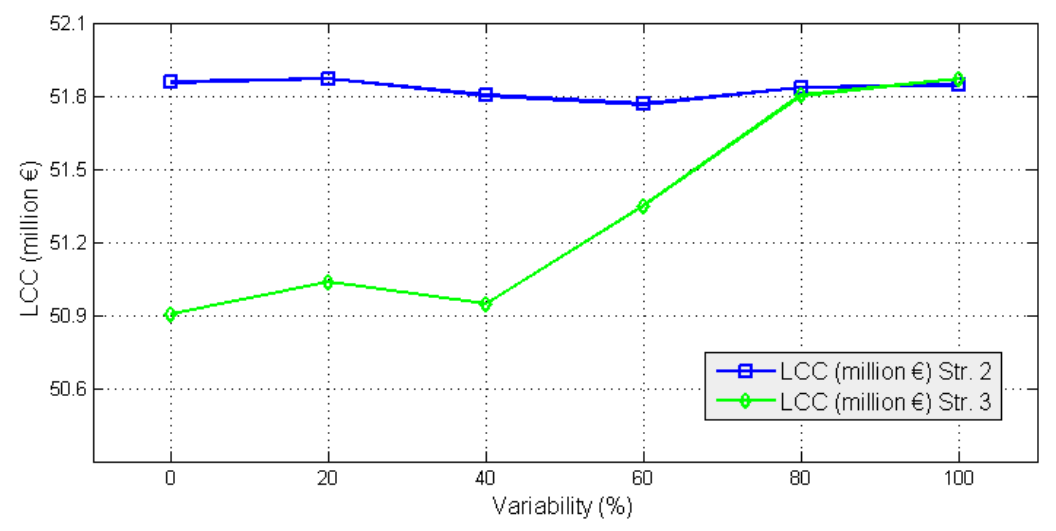

Figure 11: LCC variability

\section{Concluding Remarks}

Different opportunistic maintenance policies have been proposed for the wind power industry during the past few years, with different focus, objectives and assumptions. However, all these studies meet at a point: decision making process is always based on static reliability or age thresholds. On the contrary, the reliability thresholds proposed in the presented opportunistic maintenance model are allowed to vary according to the weather conditions. Thus, a dynamic nature has been provided to the maintenance decision making process, allowing it to be more adaptable to the specific environment circumstances.

The results obtained show that the performance of the strategies established by the dynamic reliability thresholds improve the ones proposed by the static reliability thresholds, both according to wind farm production and life cycle cost. Likewise, the dynamic opportunistic maintenance policy presented in this paper also allows to improve workers' safety, since the preventive maintenance activities are performed under the recommended weather conditions. Furthermore, as far as the authors are concerned, this opportunistic maintenance model is the first one for the sector that bears so many factors at the same time, i.e. multiple components systems with multiple failure modes, multilevel maintenance with perfect and imperfect maintenance, utilisation of own and outsourced maintenance resources, repair times for each failure mode, etc.

Future efforts will concentrate on the integration of the condition based maintenance strategies in the presented dynamic opportunistic maintenance policy. Likewise, further research will be performed to address the challenge of optimising simultaneously the maintenance strategies for several wind farms through dynamic opportunistic maintenance policies. Finally, in the case study presented there was not a remarkable wind speed seasonality, which might condition the wind farm's production, and thus, the dynamic opportunistic maintenance policy adopted. The authors will further investigate the dynamic opportunistic maintenance behaviour in wind farms where this effect is more relevant.

\section{Funding}

This research work was performed within both the context of the EmaitekPlus 2015-2016 Program of the Basque Government and the SustainOwner ('Sustainable Design and Management of Industrial Assets through Total Value and Cost of Ownership'), a project sponsored by the EU Framework Programme Horizon 2020, MSCA-RISE-2014: Marie Sktodowska-Curie Research and Innovation Staff Exchange (RISE) (grant agreement number 645733 - Sustain-Owner - H2020-MSCA-RISE-2014) and .

[1] T. Ackermann, Wind Power in Power Systems, Wiley-Blackwell, 2005. doi:10.1002/0470012684 URL http://dx.doi.org/10.1002/0470012684

[2] Anon., Global status of wind power in 2014, Global wind energy Council (2015).

URL http://www.gwec.net/wp-content/uploads/2015/03/GWEC_Global_Wind_2014_Report_LR 
[3] P. J. Tavner, J. Xiang, F. Spinato, Reliability analysis for wind turbines, Wind Energy 10 (1) (2007) 1-18. doi:10.1002/ we. 204.

URL http://dx.doi.org/10.1002/we.204

[4] M. Shafiee, Maintenance logistics organization for offshore wind energy: Current progress and future perspectives, Renewable Energy 77 (2015) 182-193. doi:10.1016/j.renene.2014.11.045 URL http://dx.doi.org/10.1016/j.renene.2014.11.045

[5] J. Kaldellis, M. Kapsali, Shifting towards offshore wind energy-recent activity and future development, Energy Policy 53 (2013) 136-148. doi:10.1016/j.enpol.2012.10.032 URL http://dx.doi.org/10.1016/j.enpol.2012.10.032

[6] Anon., The European offshore wind industry - key trends and statistics 2014, The European Wind Energy Association, EWEA (2015).

1. URL http://www.ewea.org/fileadmin/files/library/publications/statistics/EWEA-European-0ffshore-Statistics-2014. pdf

[7] E. Byon, Wind turbine operations and maintenance: a tractable approximation of dynamic decision making, IIE Transactions 45 (11) (2013) 1188-1201. doi:10.1080/0740817x.2012.726819 URL http://dx.doi.org/10.1080/0740817X.2012.726819

[8] H. Krokoszinski, Efficiency and effectiveness of wind farms - keys to cost optimized operation and maintenance, Renewable Energy 28 (14) (2003) 2165-2178. doi:10.1016/s0960-1481(03)00100-9 URL http://dx.doi.org/10.1016/S0960-1481(03)00100-9

[9] Z. Sen, Statistical investigation of wind energy reliability and its application, Renewable Energy 10 (1) (1997) 71-79. doi:10.1016/0960-1481(96)00021-3. URL http://dx.doi.org/10.1016/0960-1481(96)00021-3

[10] S. Carlos, A. Sánchez, S. Martorell, I. Marton, Onshore wind farms maintenance optimization using a stochastic model, Mathematical and Computer Modelling 57 (7-8) (2013) 1884-1890. doi:10.1016/j.mcm.2011.12.025. URL http://dx.doi.org/10.1016/j.mcm.2011.12.025

[11] F. Ding, Z. Tian, Opportunistic maintenance for wind farms considering multi-level imperfect maintenance thresholds, Renewable Energy 45 (2012) 175-182. doi:10.1016/j.renene.2012.02.030 URL http://dx.doi.org/10.1016/j.renene.2012.02.030

[12] F. P. G. Márquez, A. M. Tobias, J. M. P. Pérez, M. Papaelias, Condition monitoring of wind turbines: Techniques and methods, Renewable Energy 46 (2012) 169-178. doi:10.1016/j.renene.2012.03.003. URL http://dx.doi.org/10.1016/j.renene.2012.03.003

[13] W. Yang, P. J. Tavner, C. J. Crabtree, Y. Feng, Y. Qiu, Wind turbine condition monitoring: technical and commercial challenges, Wind Energy 17 (5) (2014) 673-693. doi:10.1002/we.1508. URL http://dx.doi.org/10.1002/we.1508

[14] M. C. Garcia, M. A. Sanz-Bobi, J. del Pico, Simap: Intelligent system for predictive maintenance, Computers in Industry 57 (6) (2006) 552-568. doi:10.1016/j.compind.2006.02.011 URL http://dx.doi.org/10.1016/j.compind.2006.02.011

[15] A. V. Horenbeek, J. V. Ostaeyen, J. R. Duflou, L. Pintelon, Quantifying the added value of an imperfectly performing condition monitoring system - application to a wind turbine gearbox, Reliability Engineering \& System Safety 111 (2013) 45-57. doi:10.1016/j.ress.2012.10.010 URL http://dx.doi.org/10.1016/j.ress.2012.10.010

[16] Anon., Managing the wind, Refocus 6 (2005) 48-51. doi:10.1016/s1471-0846(05)70402-9 URL http://dx.doi.org/10.1016/S1471-0846(05)70402-9

[17] Y. Amirat, M. Benbouzid, E. Al-Ahmar, B. Bensaker, S. Turri, A brief status on condition monitoring and fault diagnosis 485 in wind energy conversion systems, Renewable and Sustainable Energy Reviews 13 (9) (2009) 2629-2636. doi:10.1016/ j.rser.2009.06.031. URL http://dx.doi.org/10.1016/j.rser.2009.06.031

[18] A. Kusiak, Z. Zhang, A. Verma, Prediction, operations, and condition monitoring in wind energy, Energy 60 (2013) 1-12. doi:10.1016/j.energy.2013.07.051. URL http://dx.doi.org/10.1016/j.energy.2013.07.051

[19] H. Wang, H. Pham, Optimal preparedness maintenance of multi-unit systems with imperfect maintenance and economic dependence, in: Springer Series in Reliability Engineering, Springer, 2006, pp. 135-150. doi:10.1007/1-84628-325-6_7 URL http://dx.doi.org/10.1007/1-84628-325-6_7

[20] F. Ding, Z. Tian, Opportunistic maintenance optimization for wind turbine systems considering imperfect maintenance actions, International Journal of Reliability, Quality and Safety Engineering 18 (05) (2011) 463-481. doi:10.1142/ s0218539311004196.

URL http://dx.doi.org/10.1142/S0218539311004196

[21] R. Nicolai, R. Dekker, A review of multi-component maintenance models, in: Proceedings of European Safety and Reliability Conference, 2007, pp. 289-296.

URL http://www .dimat.unina2.it/marrone/dwnld/Proceedings/ESREL/2007/Pdf/CH036.pdf

[22] R. Dekker, R. E. Wildeman, F. A. van der Duyn Schouten, A review of multi-component maintenance models with economic dependence, Mathematical Methods of Operations Research 45 (3) (1997) 411-435. doi:10.1007/bf01194788. URL http://dx.doi.org/10.1007/BF01194788

[23] M. W. Sasieni, A markov chain process in industrial replacement, OR 7 (4) (1956) 148. doi:10.2307/3007561. URL http://dx .doi .org/10.2307/3007561 
[24] T. Nakagawa, D. Murthy, Optimal replacement policies for a two-unit system with failure interactions, Revue française d'automatique, d'informatique et de recherche opérationnelle. Recherche opérationnelle 27 (4) (1993) 427-438.

URL http://archive.numdam.org/ARCHIVE/RO/RO_1993_-27_4/RO_1993__27_4_427_0/RO_1993__27_4_427_0.pdf

[25] H. Wang, A survey of maintenance policies of deteriorating systems, European Journal of Operational Research 139 (3) (2002) 469-489. doi:10.1016/s0377-2217(01)00197-7. URL http://dx.doi.org/10.1016/S0377-2217(01)00197-7

[26] P. Ritchken, J. G. Wilson, (m,t) group maintenance policies, Management Science 36 (5) (1990) 632-639. doi:10.1287/ mnsc.36.5.632

URL http://dx.doi.org/10.1287/mnsc.36.5.632

[27] R. C. Vergin, M. Scriabin, Maintenance scheduling for multicomponent equipment, IIETransactions 9 (3) (1977) $297-305$. doi:10.1080/05695557708975158,

URL http://dx.doi.org/10.1080/05695557708975158

[28] J. Crocker, U. Kumar, Age-related maintenance versus reliability centred maintenance: a case study on aero-engines, Reliability Engineering \& System Safety 67 (2) (2000) 113-118. doi:10.1016/s0951-8320(99)00052-6. URL http://dx.doi.org/10.1016/S0951-8320(99)00052-6

[29] J. S. Dagpunar, A maintenance model with opportunities and interrupt replacement options, The Journal of the Operational Research Society 47 (11) (1996) 1406. doi:10.2307/3010206. URL http://dx.doi.org/10.2307/3010206

[30] X. Zheng, N. Fard, A maintenance policy for repairable systems based on opportunistic failure-rate tolerance, IEEE Transactions on Reliability 40 (2) (1991) 237-244. doi:10.1109/24.87134. URL http://dx.doi.org/10.1109/24.87134

531] Z. Tian, T. Jin, B. Wu, F. Ding, Condition based maintenance optimization for wind power generation systems under continuous monitoring, Renewable Energy 36 (5) (2011) 1502-1509. doi:10.1016/j.renene.2010.10.028 URL http://dx.doi.org/10.1016/j.renene.2010.10.028

530 [32] F. Besnard, M. Patrikssont, A.-B. Strombergt, A. Wojciechowskit, L. Bertling, An optimization framework for opportunistic maintenance of offshore wind power system, in: IEEE Bucharest PowerTech, IEEE Institute of Electrical \& Electronics Engineers, 2009. doi:10.1109/ptc.2009.5281868. URL http://dx.doi.org/10.1109/PTC.2009.5281868

[33] H. Abdollahzadeh, K. Atashgar, M. Abbasi, Multi-objective opportunistic maintenance optimization of a wind farm considering limited number of maintenance groups, Renewable Energy 88 (2016) 247-261. doi:10.1016/j.renene.2015. 11.022,

URL http://dx.doi.org/10.1016/j.renene.2015.11.022

[34] K. Atashgar, H. Abdollahzadeh, Reliability optimization of wind farms considering redundancy and opportunistic maintenance strategy, Energy Conversion and Management 112 (2016) 445-458. doi:10.1016/j.enconman.2016.01.027. URL http://dx.doi.org/10.1016/j.enconman.2016.01.027

[35] B. R. Sarker, T. I. Faiz, Minimizing maintenance cost for offshore wind turbines following multi-level opportunistic preventive strategy, Renewable Energy 85 (2016) 104-113. doi:10.1016/j.renene.2015.06.030 URL http://dx.doi.org/10.1016/j.renene.2015.06.030

[36] W. Zhu, M. Fouladirad, C. Bérenguer, A multi-level maintenance policy for a multi-component and multifailure mode system with two independent failure modes, Reliability Engineering \& System Safety 153 (2016) 50-63. doi:10.1016/j. ress.2016.03.020. URL http://dx.doi.org/10.1016/j.ress.2016.03.020

「37] M. Iqbal, M. Azam, M. Naeem, A. Khwaja, A. Anpalagan, Optimization classification, algorithms and tools for renewable energy: A review, Renewable and Sustainable Energy Reviews 39 (2014) 640-654. doi:10.1016/j.rser.2014.07.120 URL http://dx.doi.org/10.1016/j.rser.2014.07.120

[38] H. Pham, H. Wang, Imperfect maintenance, European Journal of Operational Research 94 (3) (1996) 425-438. doi: 10.1016/s0377-2217(96)00099-9. URL http://dx.doi.org/10.1016/S0377-2217(96)00099-9

[39] E. Byon, L. Ntaimo, Y. Ding, Optimal maintenance strategies for wind turbine systems under stochastic weather conditions, IEEE Transactions on Reliability 59 (2) (2010) 393-404. doi:10.1109/tr.2010.2046804 URL http://dx.doi.org/10.1109/TR.2010.2046804

[40] P. Tavner, D. M. Greenwood, M. W. G. Whittle, R. Gindele, S. Faulstich, B. Hahn, Study of weather and location effects on wind turbine failure rates, Wind Energy 16 (2) (2012) 175-187. doi:10.1002/we.538 URL http://dx.doi.org/10.1002/we.538

[41] G. Wilson, D. McMillan, Modeling the relationship between wind turbine failure modes and the environment, Gas (CCGT) 22 (2014) 6-4.

URL https://pure.strath.ac.uk/portal/files/30166175/Modeling_the_relationship_between_wind_turbine_ failure_modes_and_the_environment.pdf

[42] S. Kahrobaee, S. Asgarpoor, A hybrid analytical-simulation approach for maintenance optimization of deteriorating equipment: Case study of wind turbines, Electric Power Systems Research 104 (2013) 80-86. doi:10.1016/j.epsr.2013.06.012. URL http://dx.doi.org/10.1016/j.epsr.2013.06.012

[43] J. Andrawus, J. Watson, M. Kishk, A. Adam, The selection of a suitable maintenance strategy for wind turbines, Wind Engineering 30 (6) (2006) 471-486. doi:10.1260/030952406779994141.

URL http://dx.doi.org/10.1260/030952406779994141

[44] E. Byon, Y. Ding, Season-dependent condition-based maintenance for a wind turbine using a partially observed Markov 
decision process, IEEE Trans. Power Syst. 25 (4) (2010) 1823-1834. doi:10.1109/tpwrs.2010.2043269

URL http://dx.doi.org/10.1109/TPWRS.2010.2043269

[45] J. Carroll, A. McDonald, D. McMillan, Failure rate, repair time and unscheduled o\&m cost analysis of offshore wind turbines, Wind Energy (2015) n/a-n/sdoi:10.1002/we.1887.

URL http://dx.doi.org/10.1002/we.1887

[46] M. Yañez, F. Joglar, M. Modarres, Generalized renewal process for analysis of repairable systems with limited failure experience, Reliability Engineering \& System Safety 77 (2) (2002) 167-180. doi:10.1016/S0951-8320(02)00044-3 URL http://www.sciencedirect.com/science/article/pii/S0951832002000443

[47] A. Karyotakis, On the optimisation of operation and maintenance strategies for offshore wind farms, Ph.D. thesis, University College London (UCL) (2011). URL http://discovery.ucl.ac.uk/id/eprint/1302066

[48] J. S. González, A. G. G. Rodriguez, J. C. Mora, J. R. Santos, M. B. Payan, Optimization of wind farm turbines layout using an evolutive algorithm, Renewable Energy 35 (8) (2010) 1671-1681. doi:10.1016/j.renene.2010.01.010.

URL https://doi.org/10.1016\%2Fj.renene.2010.01.010

[49] R. Karki, J. Patel, Reliability assessment of a wind power delivery system, Proceedings of the Institution of Mechanical Engineers, Part O: Journal of Risk and Reliability 223 (1) (2008) 51-58. doi:10.1243/1748006xjrr218. URL http://dx.doi.org/10.1243/1748006XJRR218

[50] M. Niazi, A. Hussain, Agent-based computing from multi-agent systems to agent-based models: a visual survey, Scientometrics 89 (2) (2011) 479-499. doi:10.1007/s11192-011-0468-9. URL http://dx.doi.org/10.1007/s11192-011-0468-9

[51] J. Banks, Discrete event simulation, in: Encyclopedia of Information Systems, Elsevier BV, 2003, pp. 663-671. doi: 10.1016/b0-12-227240-4/00045-9.

URL http://dx.doi .org/10.1016/BO-12-227240-4/00045-9

[52] M. Martin-Tretton, M. Reha, M. Drunsic, M. Keim, Data collection for current us wind energy projects: Component costs, financing, operations, and maintenance, Contract 303 (2012) 275-3000.

595

[53] M. Laguna, R. Martí, The optquest callable library, in: Optimization Software Class Libraries, Springer, 2003, pp. 193218. doi:10.1007/0-306-48126-X_7.

URL http://link.springer.com/chapter/10.1007/0-306-48126-X_7

[54] F. Glover, J. P. Kelly, M. Laguna, The optquest approach to crystal ball simulation optimization, Graduate school of Business, University of Colorado 16.

URL https://www.researchgate.net/profile/Fred_Glover/publication/267771945_THE_OPTQUEST_APPROACH_TO_ CRYSTAL_BALL_SIMULATION_OPTIMIZATION/links/545d0a330cf295b5615e665f .pdf

[55] I. Yun, B. Park, Application of stochastic optimization method for an urban corridor, in: Proceedings of the 2006 Winter Simulation Conference, Institute of Electrical \& Electronics Engineers (IEEE), 2006. doi:10.1109/wsc.2006.322918. URL http://dx.doi.org/10.1109/WSC.2006.322918

556] F. Glover, A template for scatter search and path relinking, Lecture notes in computer science 1363 (1998) 13-54. doi: 10.1007/BFb0026589. URL http://link.springer.com/chapter/10.1007/BFb0026589

[57] M. Laguna, R. Martí, Experimental testing of advanced scatter search designs for global optimization of multimodal functions, Journal of Global Optimization 33 (2) (2005) 235-255. doi:10.1007/s10898-004-1936-z

URL http://link.springer.com/article/10.1007/s10898-004-1936-z

[58] P. C. Rodríguez, N. J. Simón, Wind Turbines: Safety measures in maintenance activities, Instituto Nacional de Seguridad e Higiene en el Trabajo (2014). 